Arne Zeschel / Kristel Proost

\title{
Grain size issues in constructicon building - and how to address them
}

1 Introduction

2 German PO constructions in existing resources

2.1 General dictionaries

2.2 Valency dictionaries

2.3 Dictionaries of prepositions

2.4 Reference grammars

2.5 Monographic studies

2.6 Evaluation
3 Grain size problems in the analysis of German nach-POs

3.1 Granularity of meaning

3.2 Granularity of form

4 Towards a constructicon

4.1 General design features

4.2 An illustration

5 Summary and conclusion

6 Bibliography

\begin{abstract}
Novel formats of construction-based description hold great potential for phenomena that fall through the cracks in traditional kinds of linguistic reference works. On the example of German verb argument structure constructions with a prepositional object, we demonstrate that a construction-based description of such phenomena is superior to existing lexicographic and grammaticographic treatments, but that it also poses a number of new problems. The most fundamental of these relates to the fact that construction-based analyses can be proposed on different levels of abstraction. We illustrate pertinent problems relating to the precise identification of constructional form and meaning and suggest a multi-layered descriptive format for web-based electronic reference constructica that can accommodate these challenges. Semantically, the proposed solution integrates both lumping and splitting perspectives on constructional grain size and permits users to flexibly zoom in and out on individual elements in the resource. Formally, it can capture variation in the number and marking of realised arguments as found in e.g. passives and transitivity alternations. Aspects of the theoretical controversy between Construction Grammar and Valency Theory are addressed where relevant, but our focus is on questions of description and the practical implementation of construction-based analyses in a suitable type of linguistic reference work.
\end{abstract}

Keywords: prepositional object construction, conative construction, constructional synonymy, constructional ambiguity, allostructions

\footnotetext{
Arne Zeschel, Leibniz-Institut für Deutsche Sprache (IDS), Lexik/Pragmatik, Mannheim, Germany, e-Mail: zeschel@ids-mannheim.de

Kristel Proost, Leibniz-Institut für Deutsche Sprache (IDS), Lexik, Mannheim, Germany, e-Mail:proost@ids-mannheim.de
}

https://doi.org/10.1515/lex-2019-0005 


\section{Introduction}

Constructionist approaches to language provide a new perspective on structures that question a neat separation of lexical and grammatical phenomena. By propagating an integrated description of such elements, they also challenge the established distribution of labour between traditional dictionaries on the one hand and traditional reference grammars on the other. Since neither conventional dictionaries nor grammars provide a suitable format for such integrated descriptions, suggestions have been made in recent years for novel, construction-based descriptive resources that seek to overcome the received dichotomy of lexicography and grammaticography (Fillmore/ Lee-Goldman/Rhomieux 2012, Boas 2014, Ziem 2014, Herbst 2017). Of course, the switch to a construction-based perspective also raises a number of new questions and problems of its own that need to be addressed in the course of implementing it in a descriptive reference work. One of the most fundamental of these problems relates to the precise identification of the units of description and their demarcation from distinct, but related elements in the constructional inventory of a language: constructional form-meaning pairings can be defined on different levels of abstraction, and it is not self-evident which one of these should constitute the focus of attention for a given purpose. We refer to this question as the grain size problem of constructional description.

Our discussion focuses on prepositional object (PO) constructions in German. In such argument structure constructions, the verb combines with a PP argument with a specific prepositional head that is traditionally analysed as lexically selected by the verb and hence invariant. On closer inspection, however, it is not uncommon for a verb (in the same reading) to occur with more than just one such preposition, as the following combinations of fragen 'ask' with the four prepositions nach, über, um and zu show:

(1) a. Wir fragten Jugendliche nach ihrer Meinung.

'We asked youths about/for their opinion'

(Berliner Zeitung, 16.06.2003)

b. Wir fragten einige Schüler über ihre Meinung.

'We asked several pupils about/for their opinion'

(Rheinzeitung, 10.12.2013)

c. Als neuer Kapitän hat er Köpke sehr oft um seine Meinung gefragt.

'As the new skipper, he has often asked Köpke about/for his opinion'

(Nürnberger Nachrichten, 19.05.2001)

d. Ich sprach Leute in Cafés und auf der Strasse an und fragte sie zu ihrer Meinung.

'I approached people in cafés and in the street and asked them about/for their opinion'

(St. Galler Tagblatt, 14.12.2009) 
In contrast to these examples with fragen, the expressions in (2) illustrate that the four prepositions are not generally interchangeable in German PO constructions:

(2) a. nach $/{ }^{\star} \mathrm{um} /{ }^{\star} \ddot{\mathrm{u} b e r} /{ }^{\star} \mathrm{zu}$ etwas hungern/tasten/treten

'to hunger/grope for something, to kick at something'

b. um/ ${ }^{\star}$ nach $/{ }^{\star}$ über/ ${ }^{\star}$ zu etwas bitten/fürchten/pokern

'to ask/fear/gamble for something'

c. über/ ${ }^{\star} \mathrm{zu} /{ }^{\star}$ nach/ ${ }^{\star}$ um etwas herrschen/wachen/staunen

'to rule over something, to ensure that something is done, to marvel at somehing'

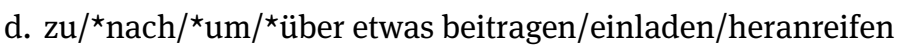

'to contribute/invite to something, to mature into something'

In section 2, we first compare and evaluate existing accounts of the different prepositional object uses of fragen in (1) in both traditional and construction-based reference works. We argue that an integrated, construction-based description is more adequate for capturing relevant similarities and differences among these and similar expressions with other verbs.

In section 3, we focus on the construction with nach 'for/after' in (1.a) and move on to a discussion of the grain size problem of constructional description. Granularity issues are addressed with respect to constructional meaning (3.1) and form (3.2). Where relevant, the discussion touches on aspects of the theoretical controversy between proponents of Construction Grammar and adherents of Valency Theory. However, our main concern is with practical implications of the descriptive grain size problem for building a construction-based reference work of German prepositional object constructions.

In section 4, we formulate general desiderata for such a resource and sketch strategies for addressing the problems identified in section 3. Using German nach-PO constructions as an example, we introduce an approach to their description that is currently developed in the project Verben und Argumentstrukturen 'Verbs and argument structures' at the Leibniz Institute for the German Language in Mannheim.

Section 5 summarises the discussion and presents our conclusions. We suggest a multi-layered web-based format for the representation of constructional generalisations that integrates both lumping and splitting perspectives on descriptive grain size and argue that such resources constitute a useful addition to the existing repertoire of linguistic reference works.

\section{German PO constructions in existing resources}

Suppose a learner (or other user of a linguistic reference work) is interested in similarities and differences between the constructions in (1). Where is relevant information to be found in existing resources, and how can it be looked up? In this section, we 
examine how the PO-constructions in (1.a-d) are covered in different types of linguistic reference works, focussing on the following questions:

(i) Semanticity: Does the resource in question provide information about any differences in meaning between the expressions in (1), and to which elements are these meanings attributed?

(ii) Coverage: Which meanings are postulated?

(iii) Accessibility: How can the relevant information be looked up?

Our comparison is based on the following selection of both general and specialised dictionaries (print and online), reference grammars and monographic reference works:

- General dictionaries: DUW = DUDEN Universalwörterbuch (2015)

- Valency dictionaries: VALBU = Valenzwörterbuch deutscher Verben (Schumacher et al. 2004) and E-VALBU (n.y., online version of VALBU)

- Dictionaries of prepositions: Lexikon deutscher Präpositionen (Schröder 1986), Handbuch für die Bestimmung und Annotation von Präpositionsbedeutungen im Deutschen (Kiss et al. 2016)

- Reference grammars: Grammatik der deutschen Sprache (Zifonun/Hoffmann/ Strecker 1997)

- Monographic studies: Präpositionalobjekt vs. Adverbial: Die semantischen Rollen der Präpositionalobjekte (Höllein 2019)

Sections 2.1-2.5 address questions (i)-(iii) with respect to these particular resources. In section 2.6, we summarise our observations and evaluate the informativeness and practical usability of these reference works with regard to our objective.

\subsection{General dictionaries}

Semanticity: Where they are assumed, PO-specific meanings could be ascribed either to governing verbs (in special senses) and/or to the PO-preposition. In DUW, the entry for fragen (DUW, p. 636) mentions fragen nach and fragen um, but not fragen über and fragen zu. Conversely, special relational uses ("as a dependent of specific verbs") are postulated for all four prepositions.

Coverage: In the entry for fragen (DUW, p. 636), fragen nach is associated with three distinct senses: 'enquire' (sense 2a), 'to care about somebody/something' (sense 2b), ${ }^{2}$

1 Cf. Ich habe sie nach ihren Eltern gefragt 'I enquired about her parents'.

2 Cf. Wer fragt nach der einsamen, alten Frau? 'Who cares about the lonely old woman?'. 
and 'request' (sense 3). ${ }^{3}$ The same 'request' sense is also associated with fragen um. In the preposition entries, uses that are classified as lexically selected ("in Abhängigkeit von bestimmten Verben" 'as a dependent of specific verbs') are generally not given an actual semantic characterisation apart from their identification as "relational". At the same time, some expressions that are traditionally analysed as PO uses (e.g. jemanden zu etwas einladen 'to invite somebody to something') are nevertheless listed under regular, semantically more substantive senses of the preposition (e.g. 'expresses the purpose, reason, goal or result of an action' in the case of the $z u$-PP with einladen).

Accessibility: Distinct PO meanings are not explicitly postulated and hence impossible to look up. In order to get at the meaning(s) of e.g. nach-POs, a user would thus have to (i) look up nach in order to find that e. g. fragen 'ask', greifen 'grasp, reach out for' and streben 'strive' are verbs that lexically select its special "relational” use, (ii) look up fragen, greifen and streben and locate the relevant uses with nach in these entries (insofar as they are listed there), and (iii) work out what the senses of these different verb+PO-nach combinations have in common.

\subsection{Valency dictionaries}

Semanticity: Valency dictionaries directly associate different verbal complementation patterns (such as our four PO constructions) with distinct meanings. These meanings are attributed to pattern-specific verb senses.

Coverage: The entry of fragen in VALBU (Schumacher et al. 2004) lists three such form-meaning patterns with nach and one with um (387-389). No mention is made of fragen über and fragen $z u$. The patterns with nach are associated with the three meanings 'to care about somebody/something', 'enquire' and 'search'. The pattern with um is associated with the meaning 'to request'. Patterns with similar meanings are found in the entries of some other PO-verbs (cf. e. g. kämpfen um in the entry for kämpfen 'fight'), ${ }^{4}$ but missing in others. For instance, there is no mention of schwimmen um (as in um den Titel schwimmen 'to swim for the title') in the entry for schwimmen 'swim'. Moreover, VALBU only covers a fairly restricted number of verbs to begin with (638 lemmas), to the effect that only few of the verbs relevant to the PO constructions with nach and um have an entry in VALBU.

3 Cf. Er hat schon an vielen Stellen nach Arbeit gefragt 'He has asked for work in many places'. 4 VALBU gloss (Schumacher et al. 2004: 476): “Jemand bemüht sich energisch darum, jemanden/ etwas [keine Restr.] zu bekommen” ('somebody struggles to obtain somebody/something').

5 cf. Schumacher et al. 2004: 649-651. 
Accessibility: In print dictionaries like VALBU, valency patterns are accessible only via the lexical entries of associated verbs. In other words, patterns cannot be searched for directly. The electronic version of VALBU, E-VALBU, does allow searches for different types of complements and valency patterns ("Satzbaupläne”). Hence, a user interested in prepositional object constructions could search for complements of the form ' $\mathrm{K}_{\text {prp }}$ ' ("Präpositivkomplement”, i. e. a PP-complement) or valency patterns like ' $\mathrm{K}_{\text {sub }},\left(\mathrm{K}_{\mathrm{akk}}\right)$, $\mathrm{K}_{\mathrm{prp}}$ ' (i. e. a pattern consisting of an NP-complement in the nominative, an optional NP-complement in the accusative and a PP-complement, among others). ${ }^{6}$ However, complements or valency patterns involving a specific preposition (or other lexical item) cannot be searched for. Moreover, search criteria can only be specified on the basis of structural criteria, so that it is not possible to retrieve valency patterns with a specific meaning (component).

\subsection{Dictionaries of prepositions}

Semanticity: In contrast to much of the older literature on German prepositional objects (e.g. Engelen 1975: 111, Pittner 1996: 36-37), newer reference works on prepositions and prepositional meanings (such as Kiss et al. 2016) do not assume that a governed preposition (i. e. a lexically selected PO-preposition) is necessarily semantically empty. Instead, the semantic contentfulness of PO prepositions is seen as gradient, ranging from transparently motivated cases to purely relational elements without an autonomous meaning. It follows that certain PO uses are given a semantic characterisation, whereas others are merely listed as unanalysed "governed uses”.

Coverage: Schröder (1986) postulates seven different senses for nach. Examples with fragen are not mentioned, but could probably be assigned to his category of "purposive” uses ("gibt Zweck einer Handlung an" 'specifies the purpose of an action', p. 156). The purposive sense of nach is divided into four different subsenses, with co-occurring verbs denoting attempts at either 'obtaining', ' 'hitting', 'looking after'"

\footnotetext{
6 A search in E-VALBU for complements of the type of ' $K_{p r p}$ ' yields 452 verbs/1101 verb senses; a search for the valency pattern ' $\mathrm{K}_{\text {sub }},\left(\mathrm{K}_{\text {akk }}\right), \mathrm{K}_{\mathrm{prp}}$ ' returns 25 verbs/31 verb senses.

7 "um etwas zu erlangen, zu bekommen" 'in order to obtain, aqcuire something', with examples nach jemandem/etwas suchen/greifen/dürsten 'to search/grasp/thirst for somebody/something'.

8 "um etwas/jemanden zu treffen" 'in order to hit somebody or something', with examples nach jemandem/etwas schlagen/schießen/treten 'to hit/shoot/kick at somebody/something'.

9 "um zu erfahren, wie es jemandem geht” 'in order to find out about somebody's well-being', with examples nach jemandem/etwas sehen/schauen 'to look after somebody'.
} 
or 'fetching/summoning'10 the PO participant. Following Schröder, Kiss et al. (2016: 149) also postulate a purposive sense for nach (without further subdistinctions), which includes both governed and non-governed uses of the preposition. ${ }^{11}$ The verb schlagen 'hit', for instance, is used to exemplify the purposive sense of nach (p. 146), but is also included on the list of unanalysed "governed uses" (p. 150). Our target verb fragen is found on the same list (along with 52 other verbs), but it is not clear whether the preposition in fragen nach is assumed to instantiate the purposive sense (as in the case of schlagen) or whether it is analysed as a meaningless syntactic marker. For $u m$, Kiss et al. (2016: 191) postulate a purposive sense, too. ${ }^{12}$ No mention is made of fragen here, but the purposive sense of $\mathrm{um}$ is exemplified in connection with the closely related verb bitten 'ask, plead', which is listed as a governed use of um at the same time (p. 193). No such purposive sense is mentioned for um in Schröder (1986: 178-183). For über, Kiss et al. (2016: 183) postulate a "reference point" sense that would be compatible with fragen über. In addition, they also postulate a "topic" sense, but the only examples given for this sense involve combinations of über with a noun. Though a large number of verbs, including communication verbs, is mentioned among the governed uses of über, fragen is not mentioned as one of them. A "reference point" or other sense relevant to fragen über or fragen $z u$ is not mentioned in the entries of these prepositions in Schröder (1986: 172-178, 224-237). The preposition $z u$ is not discussed in Kiss et al. (2016) at all.

Accessibility: PO constructions are covered in the entries of individual prepositions. Kiss et al. (2016) list prepositions not only alphabetically, but also according to the meanings that they encode. It is therefore possible to directly look up PO constructions with a certain preposition and PO constructions with a certain semantics (according to the authors). This means that once a relevant sense is identified (such as the purposive sense of nach), it is possible to look up other prepositions that are assigned to the same category (in this case, auf, für, um and wegen). By contrast, a verb index is missing, so that it is not possible to look up the PO prepositions occurring with a specific verb (or other governor) in the underlying dataset.

10 "um etwas/jemanden herzuholen" 'in order to fetch or summon somebody or something', with examples nach jemandem/etwas telefonieren/rufen/schicken 'to telephone/call/send after somebody or something'.

11 Kiss et al. (2016: 146) maintain that "in some such cases" 'in einigen Fällen' the preposition is lexically selected. Examples adduced for the purposive sense of nach include combinations with schnappen 'snatch', schlagen 'hit' and rufen 'call'.

12 “[D]rückt den Zweck, das Ziel, die Absicht oder das ersehnte (abstrakte) Objekt aus, der/die/das hinter einer Handlung stehen“ 'denotes the purpose, the goal, the intention or the desired (abstract) object underlying the activity'. 


\subsection{Reference grammars}

Semanticity: Of the four prepositions in the PO constructions in (1), only über is dealt with in the most comprehensive contemporary German reference grammar, Zifonun/ Hoffmann/Strecker's (1997: 2128-2129) Grammatik der deutschen Sprache. The authors classify prepositional objects semantically and explore the relation between uses of prepositions in prepositional objects vs. adverbials, taking the prepositions an, auf, für and mit as examples (p. 2113-2114). Short descriptions are provided for in and über. The prepositions nach, um and $z u$ are mentioned only in passing. POs with über are assigned a "topic" or "theme" role when they combine with verbs of communication or psych-verbs. In connection with the latter, the authors furthermore postulate an "intimation of causality". ${ }^{13}$ This suggests that the interpretation of a given PO is taken to be driven by the meaning of the governing verb.

Coverage: According to Zifonun/Hoffmann/Strecker (1997: 2129), a PP headed by über denotes a "topic"14 when combined with communication verbs like diskutieren 'discuss', reden 'talk' and sprechen 'speak', or psych-verbs like sich freuen 'to be glad'. The 'topic' sense is analysed as a metaphorical extension of a more concrete 'covering' sense of über ("bedecken” 'cover', as in Dinge über den ganzen Raum verstreuen 'to scatter things all over the room'): as a result of the verb event, the abstract topic is understood to be "covered" by the subject's mental or communicative activity. Preposition variation in über-POs is mentioned in passing in connection with sich über etwas freuen vs. sich an etwas freuen 'to delight in something', where the variant with über is said to imply a "separation" (p. 2119) between the EXPERIENCER and the topic, whereas the an-variant is said to imply proximity and "emotional affectedness" (p. 2119). However, variation with nach, $u m$ and $z u$ is not dealt with since none of the other three prepositions is discussed.

Accessibility: PO meanings are suggested for a few prepositions only, as is information on the semantic contribution of the verb to these constructions. It is neither possible to look up the verbs that occur with a given PO preposition nor the PO prepositions that occur with a given verb.

13 "Bei den emotionenbezeichnenden Ausdrücken kommt eine kausale Note hinzu" (Zifonun/Hoffmann/Strecker 1997: 2129).

14 Or "theme" (the German original reads "Thema"). 


\subsection{Monographic studies}

Semanticity: On Höllein's (2019) construction-based account of German prepositional objects, the four structures in (1) are directly associated with four different meanings. For conventionalised verb+PO combinations, these meanings are ascribed to complex patterns comprising the verb, the preposition and a specific case. For productively coined instances (i.e. non-conventional verb+PO combinations), they are ascribed to the preposition-case combination alone (p. 75). Either way, the postulated meanings are characterised as (PO-specific) semantic roles attaching to the $\mathrm{PO}$ (or $\mathrm{PO}+$ verb pattern).

Coverage: Two semantic roles are distinguished for POs with nach and dative case. The first is dubbed "QUAESITUM" and characterised as that of an "entity being sought" (p. 233). ${ }^{15}$ The second is called "KRITERIUM" 'criterion' (p. 236) and said to designate a "measure". ${ }^{16}$ POs with über and accusative case are associated with the roles "INTELLEKTUELLES THEMA" 'intellectual topic', paraphrased as the "object or content of intellectual activity" (p. 241), ${ }^{17}$ and "INFERIOR" 'inferior', defined as "a hierarchically subordinate entity" (p. 246). ${ }^{18}$ For um and accusative case, Höllein proposes the category "ACCIPIENDUM", which designates an "entity to be obtained" (p. 255). ${ }^{19}$ Finally, POs with $z u$ and dative case are said to carry the role "RESULTATUM", which designates a "result". ${ }^{20}$ Our target verb fragen is on the lists of QUAESITUM and ACCIPIENDUM verbs that come with the descriptions of these categories of nach-and um-POs. It is not mentioned among the verbs that occur with an über-PO, but its near synonym befragen 'question' is listed among the INTELLEKTUELLES THEMA 'topic' verbs with über. POs with $z u$ also occur with certain communication verbs like raten 'advise', überreden 'persuade' and überzeugen 'convince', but the role of the PO in jemanden zu etwas fragen is different - it does not designate a "result", but rather a "topic", very much like in the case of über. Similar uses also exist for other communication verbs like reden 'talk', sprechen 'speak', diskutieren 'discuss' and others, but Höllein does not mention a PO-role 'topic' (or similar) for $z u$.

15 eg. Sie streben nach Glück, Geld, Gesundheit 'They strive for happiness, money, health' (Höllein 2019: 233).

16 eg. Nichts verläuft nach Plan 'Nothing goes according to plan' (Höllein 2019: 236).

17 eg. CDU und FDP streiten über die Bildungspolitik 'CDU and FDP quarrel over educational policy' (Höllein 2019: 241).

18 eg. Das Persönlichkeitsrecht siegte über die Kunstfreiheit 'Personal rights triumphed over freedom of art' (Höllein 2019: 246)

19 eg. Sie kämpfen um den „Comedy Pokal“ “They fight for the „Comedy Cup“” (Höllein 2019: 255-256) 20 eg. Bewegungen verschmelzen zu einer Symphonie 'Movements merge into a symphony' (Höllein 2019: 282) 
Accessibility: Postulated PO meanings are listed in separate sections for each preposition+case combination and also summarised in a tabular overview of the full range of postulated constructions with accompanying examples (pp. 288-290). Verbs found to occur in a given construction (in the corpus study underlying the analysis) are listed individually as part of the constructional description. However, a global verb index is missing, so it is not possible to look up the PO-patterns that are attested with a given verb.

\subsection{Evaluation}

To conclude this section, let us briefly wrap up and assess what the five types of reference works in our comparison have to say about the constructions in (1).

General dictionaries: In DUW, the treatment of governed uses of a preposition that is selected by particular verbs does not suggest any kind of semantic systematicity and motivation in the relationship between these elements. Where such governed uses are mentioned in the entry of a preposition, the preposition is claimed to express "a relation", but there is no information about the precise nature of that relation or the entities related..$^{21}$ At the same time, some expressions that are commonly analysed as POs are also supplied as illustrations of regular lexical (i.e. semantically more substantive) uses of the preposition in question. Where PO constructions are mentioned in the entry of a governing verb, appropriate construction-specific senses are postulated for this verb. As a result, DUW lists e. g. 'search by diving', 'search by digging' and 'search with the help of drilling devices' as semantically parallel polysemies of tauchen 'dive', graben 'dig' and bohren 'drill' when they combine with a nach-PO. This solution is unconvincing, since it ascribes meaning components to these verbs that arise only in connection with a specific complement, and hence misses an important semantic generalisation. It is furthermore impressionistic, since many other verbs that occur in this construction (cf. Proost 2017 for an overview) have no such sense listed in their entries. We conclude that DUW (and similar kinds of dictionaries in general) are not well-suited for our purpose.

Valency dictionaries: From a pattern-oriented perspective, the treatment of PO constructions in valency dictionaries like (E-)VALBU is likewise unsatisfactory. In our case, only few verbs that are relevant to the constructions in (1) are covered in the dictionary, and even where they are, their occurrence with these constructions is

21 For instance, the PO sense of $z u$ is represented as follows: "kennzeichnet in Abhängigkeit von anderen Wörtern verschiedener Wortart eine Beziehung” 'marks a relation, as a dependent of words of different parts of speech'. 
not exhaustively documented (cf. fragen über, fragen $z u$ ). Apart from these empirical issues, a more serious drawback is the practice of listing valency patterns and their associated meanings solely in the entry of individual valency carriers, which has the effect of obscuring similarities and potential generalisations over identical patterns for different verbs. ${ }^{22}$ In principle, this problem is easily remedied by providing electronic versions of such dictionaries that also permit appropriate kinds of pattern searches in the underlying database. In the case of E-VALBU, however, this functionality leaves to be desired, since it is not possible to filter the results for prepositional patterns with a specific head. As a result, relevant information about the constructions in (1) is not directly accessible to the user, but (at best) hidden in the entries of some instantiating verbs. If pattern meanings were also represented in a generalised, verb-independent format, this would furthermore permit an onomasiological access strategy that retrieves patterns with a certain designated meaning, something which is not possible in E-VALBU either. We conclude that for users with an interest in valency patterns rather than valency carriers, currently available resources like (E-) VALBU are of limited usefulness, too.

Dictionaries of prepositions: By contrast, preposition-based accounts like Schröder (1986) and Kiss et al. (2016) permit direct access to verbal constructions involving a particular PO preposition. Naturally, such reference works can also offer a more detailed account of the meaning and combinatorial properties of these items than either general or valency dictionaries since the latter have a much broader ground to cover. Moreover, where such works systematise the postulated meanings further (i.e. across different prepositions), they also open onomasiological perspectives on the data (cf. Kiss et al. 2016: 218-403). However, in both resources consulted here, semantically substantive descriptions are not in fact provided for all uses of the investigated items. Both reference works also posit a sizeable number of "governed uses" of the prepositions covered. Kiss et al. assume that such uses may or may not be semantically contentful, but do not mark individual items on their lists accordingly. At any rate, unless a given $\mathrm{V}+\mathrm{P}$ combination on these lists also happens to be adduced among the examples of a semantically substantive use of the preposition in question, it is not analysed any further: even though semantic similarities between these items are often evident, the verbs, nouns and adjectives that are enumerated for a particular governed preposition are simply listed alphabetically. For some items, however, the possibility of a semantic analysis is at least hinted at. An example is über, for which

22 Even if the goal is to look up information about a certain verb rather than a specific pattern/ construction, it is still interesting to see which semantic distinctions in the dictionary entry are truly verb-specific, and which properties show in connection with many different verbal fillers of the same syntactic pattern. In case the interest is with a given pattern/construction itself rather than an individual verb, the verb-centered presentation of the data makes it impossible to look up the requested information directly. 
Kiss et al. (2016: 413) quote Schmitz' (1964) classification of governed uses into a number of different semantic classes. ${ }^{23}$ No such hints are given for nach and $u m$, and $z u$ is not covered in the handbook at all. We conclude that existing dictionaries and handbooks of prepositions like Schröder (1986) and Kiss et al. (2016) do provide clues to the constructions in question that are both descriptively substantive and readily accessible, but do not fully exhaust their analytical potential.

Reference grammars: Zifonun/Hoffmann/Strecker (1997) argue against the traditional view that PO-prepositions are meaningless (an assumption that still survives in other widely used reference works such as e.g. the latest edition of the DUDEN Grammatik, cf. DG 2016: 615, 618, 852). Instead, they suggest that the original local meaning of a preposition often remains visible when the preposition introduces a PO (cf. the remarks on über above). Nevertheless, the chapter on prepositions and their meanings remains highly sketchy, and a user interested in differences between the constructions in (1) would be at a loss as to their similarities and differences on the basis of the information provided there. Even though it is generally acknowledged that associations between PO verbs and governed prepositions are not only grammatically relevant, but also memorised ("lexically selected" rather than fully predictable and compositional, a possible semantic motivation of their association notwithstanding), it seems to go against the grain of traditional grammaticography to actually list (and group) the relevant pairings. As a result, the grammar neither provides an index of PO-prepositions occurring with a given verb, nor of the verbs occurring with a given PO-preposition, let alone a comprehensive characterisation of the meanings that these constructions convey. To be fair, there exist exceptions in the field (like e. g. Helbig/Buscha 2017, Schulz/Griesbach 1982, Weinrich 1993) that devote more attention to the topic and indeed even list individual verbs, nouns and adjectives that conventionally combine with a given preposition. Being general reference grammars with a much more comprehensive descriptive scope, however, also these treatments still remain much too general and impressionistic to account for actual usage preferences, asymmetries and overlaps between the individual constructions in (1). We conclude that traditional grammaticographic reference works fail to specify the information we are looking for, too.

Monographic studies: On the one hand, monographic studies with a closely restricted thematic focus (like Höllein 2019) can be expected to provide the greatest wealth of detail on a given linguistic phenomenon. On the other hand, such publications are not primarily designed as reference works for the general public that are also consulted by non-linguists. As may be expected of such a monograph, Höllein (2019) is

23 According to Schmitz (1964: 69-75), über is used with "verbs of ruling” 'Verben des Herrschens', "verbs of thinking and speaking" 'Verben des Denkens und Redens' and "verbs of emotion and its expression” 'Verben der Gemütsbewegung und ihrer Äußerung'. 
a case in point: expanding on seminal work by Rostila (2005, 2007, 2014, 2015, 2018), the study takes important steps towards an empirically substantiated construction-based description of the German prepositional object system that offers the first comprehensive systematisation of the semantic load of a sizeable proportion of these constructions in present day German. At the same time, a substantial part of the book is nevertheless not concerned with actual language description, but with the conceptual foundations of framing the phenomenon of "prepositional object constructions" in a manner that is analytically rewarding, and with theoretical implications of the obtained empirical results. Descriptively, his account leaves room for improvement in our view: not surprisingly in view of its impressive coverage (13 different PO prepositions in 17 different preposition+case-combinations), the study provides only fairly coarse-grained semantic characterisations of the targeted constructions, and both the number of postulated meanings/PO-roles and the assumed boundaries between these categories are often debatable: ${ }^{24}$ regarding our example in (1), the case of (etwas) $z u$ etwas fragen (sagen 'say'/anmerken 'note'/fordern 'demand'...) in (1.d) does not fit the single postulated semantic category of $z$-POs ("RESULTATUM"), and also the semantic distinction between the PO-roles "QUAESITUM" (nach), "ACCIPIENDUM” (um) and "INTELLECTUAL TOPIC" (über) is actually unclear in our view (cf. section 3). Nevertheless, the construction-based description in Höllein (2019) clearly provides the most sophisticated account of the expressions in (1) in our comparison.

Summing up, it is difficult to learn about similarities and differences between the four constructions in (1) on the basis of most kinds of established linguistic reference works. The reason is that relevant semantic, lexical collocational and grammatical properties of these constructions are intertwined in ways that cut across the established division of labour between traditional dictionaries and grammars. Traditional dictionaries (be they general or specialised) are supposed to list the meaning and/or combinatorial potential of individual lexical items. They are not the place to look for regularities regarding the use of similar lexical items within a given grammatical environment. By contrast, traditional grammars seek to formulate more or less general rules according to which such items can be strung together. They are not the place to look for detailed semantic and collocational information about the compatible fillers of each and every individual member of the myriad of constructions in a language. As a result, many linguistic phenomena that are neither atomic words (or fully fixed multiword expressions) nor highly general grammatical rules and principles more or less fall through the cracks in either type of reference work. To overcome this problem,

24 For instance, Höllein (2019) lists only two different meanings for POs with the preposition vor, where Zeschel (2019) distinguishes five that are furthermore broken down into a total of 29 semantically coherent subtypes. This contrast is not just a question of analytical perspective but also of empirical scope, since the more finegrained analysis covers a number of constructions that are not mentioned in Höllein (2019). 
novel formats of documentation are required that provide an integrated description of constructional form, meaning and conventional usage. For English, some resources are already available that seek to overcome at least some of the problems sketched in this section. ${ }^{25}$ For German, such resources still remain a desideratum.

As indicated in the introduction, however, the switch to a construction-based description also raises new problems of its own. In the following section, we will illustrate perhaps the most fundamental of these problems on the example of the construction with nach in (1.a). The question to be answered is the following: supposing the insufficient descriptions in traditional dictionaries and reference grammars were to be supplanted with a construction-based account - then how can the construction in question be delineated in the first place?

\section{Grain size problems in the analysis of German nach-POs}

Before a construction can be described, it must be identified and defined in some way to begin with. This means that it must be (i) laid out in its internal category structure (by identifying and relating possible variants), and (ii) differentiated from other, related elements in the system in a certain way (by establishing maximally distinctive, construction-defining properties that merit its inclusion as an independent unit of description). ${ }^{26}$ The granularity problem reflects the dilemma that both kinds of distinctions - internal differentiation into subtypes, and external differentiation from other elements of the constructicon - can be drawn on different levels of abstraction.

The problems involved in this step are of course not peculiar to constructicography. When studying word meaning, for instance, access to relevant data may be easier than in studies of constructional meaning, since concrete word forms can be retrieved directly from a corpus (in contrast to lexically unfilled, flexibly ordered and structurally discontinuous grammatical constructions). However, also lexical studies must still decide which tokens in the dataset actually instantiate the intended type, thereby imposing a boundary between supposedly relevant cases of variation on the

25 Examples are the Erlangen Valency Patternbank (http://www.patternbank.uni-erlangen.de/cgibin/patternbank.cgi), the Collins Cobuild Grammar Patterns (cf. http://arts-ccr-002.bham.ac.uk/ccr/ patgram/) and especially the Pattern Dictionary of English Prepositions (https://www.clres.com/pdep. html).

26 This is still true even if little is known about the actual mental representation of such postulated units in individual speakers' linguistic knowledge, and if the boundaries between such categories are ultimately seen as fuzzy. In other words, even if discrete boundaries between the postulated units of description (constructions) were merely a convenient descriptive fiction, it is nevertheless impossible to avoid a distinction between phenomena that are within and others that are beyond the scope of given analysis (a possible prototype structure of the investigated category notwithstanding). 
one hand and supposedly irrelevant cases of non-identity (homonymy) on the other. In addition, variation can be attributed to either polysemy or vagueness, and different dictionaries structure their descriptions of the meaning(s) of one and the same item in different ways. The same is true for constructional meanings and their conceivable subsenses. Like word meanings, the meanings conveyed by argument structure constructions can either be lumped or split: looking at the full usage spectrum of a construction, it will usually be possible to make a case that certain instances are more similar to one another than to others in some respect, so that they should be grouped together on some level. Conversely, it is usually also possible to find a difference of some sort within such groups and thus conclude that their members should be distinguished into smaller subtypes. Neither of these perspectives is inherently "right" in the sense that it is a priori superior for all intents and purposes. Instead, discrepancies between lumping and splitting accounts of both lexical and constructional meaning simply point to the fact that the semantic space covered by the element in question can be carved up in different ways (involving, among other things, different degrees of attention to detail), and potentially for good reasons in each case (cf. Tuggy 1993). What is different on the level of argument structure constructions, however, is that not even the form side of these (partially or even fully) schematic units is uncontroversially given, since it can be characterised on different levels of abstraction. We will illustrate both meaning- and form-related granularity issues in turn.

\subsection{Granularity of meaning}

Consider the expressions in (3):

(3) a. "Die Einbrecher suchen nach dem Schlüssel, und nach wenigen Minuten sind alle Möbel beschädigt.”

'The burglars search for the key, and in a matter of minutes all the furniture is damaged'

(Frankfurter Allgemeine Zeitung, 14.11.2003)

b. Hände streckten sich nach ihr aus, berührten sie.

'Hands reached out for her, touched her'

(Rheinzeitung, 19.12.2006)

c. Ohlendorf schlägt nach einer Mücke aufihrem Arm.

'Ohlendorf hits at a mosquito on her arm'

(Braunschweiger Zeitung, 26.08.2011)

d. Deshalb klingt alles, was er singt, irgendwie nach Countrymusik - einfach weil seine Stimme diese Färbung hat.

'That's why everything he sings somehow sounds like country music simply because his voice has this particular tinge'

(die tageszeitung, 15.12.2000) 
Though formally identical, the argument structures in (3) exhibit a number of semantic differences: (3.a) designates an attempt to locate the PO participant, (3.b) motion towards it, (3.c) an action directed at it and (3.d) a perceptual resemblance to this entity. Does that mean that we are dealing with four different grammatical constructions? And which of these is the construction instantiated by fragen in (1.a)?

Let us begin our discussion with Höllein's construction-based analysis reviewed in section 2.5. Recall that he distinguishes two semantic roles for nach-POs, that of an "entity being sought" (QUAESITUM) and that of a "measure" (KRITERIUM). (3.a) with the verb suchen 'search' undoubtedly fits the QUAESITUM definition very well. By contrast, combinations with klingen 'sound' as in (3.d) are assigned to the KRITERIUM category by Höllein. ${ }^{27}$ Semantically, this distinction makes sense. QUAESITUM uses have an allative meaning, i. e. the verb event is directed at the PP referent. KRITERIUM uses, by contrast, are semantically ablative: the verb event is said to match some preexistent standard of comparison, from which its properties follow. ${ }^{28}$ By this token, (3.b) and (c) should be grouped with (3.a), since they are likewise allative. But these are much too general characterisations of the meaning of these expressions (at least unless one wanted to subsume all other allative patterns with nach under one and the same construction, including concrete motion constructions like nach Island fliegen 'fly to Iceland'). Put differently, it is possible to set apart (3.d) from (3.a) to (c) on semantic grounds, but a more precise characterisation of the latter is still required. Just how specific should it be? Some further examples Höllein lists for his QUAESITUM category are given in (4):

(4) a. nach etw fragen, sich nach etw erkundigen

'to ask about something', 'to enquire about something'

b. nach etw verlangen, sich nach etw sehnen, nach etw gieren

'to desire for something', 'to yearn for something', 'to crave for something'

c. nach etw greifen, nach etw fühlen, nach etw tasten

'to grasp for something', 'to feel for something'

This analysis embodies a lumping approach. From a splitting perspective, it is not difficult to see the potential for further subdistinctions in (4): the actions that are performed with respect to the 'sought' entity are relatively similar within each group in (4.a) to (c), but relatively dissimilar across them. (4.a) has our target verb fragen and its closest semantic neighbour on Höllein's list, sich erkundigen ‘enquire’. In addi-

27 The role of the prepositional participant is maybe more aptly paraphrased as a 'reference point' or 'standard of comparison' here than as a 'measure', though. In our own analysis, this construction is said to express an ACCORDANCE (cf. section 4).

28 The ablative nature of the construal is maybe most evident in examples with metaphorical senses of motion verbs like kommen, as in Er kommt nach seinem Vater 'He resembles his father' (as opposed to the allative motion meaning in Er kommt nach Mannheim 'He is coming to Mannheim'). 
tion, he mentions a number of verbs like schreien 'scream', rufen 'call' and telefonieren 'telephone' that likewise evoke communication scenarios, albeit not the specific one of 'requesting' (unless used in the nach-construction). By contrast, the verbs in (b) do not designate actions at all, but rather a certain mental disposition ('desiring'). Yet further removed from fragen are the verbs in (c) with their more concrete meanings of reaching out for an entity with one's hands.

\subsubsection{Splitting problems}

Other analyses, like Proost (2015, 2017), assume the same 'search'-meaning as Höllein (2019), but reserve it for examples like (4.a) and (b), whereas (4.c) is assigned to a separate "conative" construction with a distinct meaning ('directing an action at something', cf. also Goldberg 1995: 63; Perek 2014, 2015: 94-98; and, from a non-constructionist perspective, Levin 1993: 41-42). More precisely, Proost analyses only some expressions of the type in (4.c) as conatives, so that the distinction between the two meanings in fact cuts across the grouping in (4.c):

(5) a. Paula griff gierig nach der Speisekarte.

'Paula greedily grasped for the menu'

(Tages-Anzeiger, 20.02.1997)

b. Er fühlte in seinem Rucksack nach den zwei Plastiktafeln mit den Zehn

Geboten.

'He felt in his knapsack for the two plastic plates with the Ten Commandments'

(taz, 14.12.2015)

In these sentences, both greifen 'grasp' and fühlen 'feel' designate hand motor actions that are directed at a goal: they are meant to establish contact with the PO participant, and the contact is in both cases concrete and physical rather than abstract and mental. But only the sentence with greifen implies that the subject referent knows ${ }^{29}$ the position of the goal, and that the motion directed at it follows a straight trajectory intended to culminate in this position. In other words, the PO participant is not so much something that is being 'sought' here (insofar as this suggests that it needs to be found or discovered), but arguably more fittingly characterised as something at which

29 Of course, the subject referent's assumption may still be wrong. A sentence like Else griff blind nach Feuerstein und Zunder, doch die Sachen lagen nicht an ihrem Platz (Bonn, Susanne: Der Jahrmarkt zu Jakobi, 2011 [novel, DeReKo]) 'Else reached for flint and tinder without looking, but they were not where they belonged' does not entail that the goal is actually where the agent presumes it to be. Still, the use of greifen 'grasp' rather than fühlen 'feel' or tasten 'grope' implies that the action is directed at a specific presumed location (rather than geared at identifying this location in the first place). 
the verb action 'is directed'. By contrast, example (5.b) does not suggest a direct thrust at the targeted entity. Rather, the verb fühlen evokes a scenario of tentatively rummaging about within the general area of its presumed location, which makes the sentence quite compatible with the supposedly distinct 'search'-meaning of the expressions in (4.a) and (b). Hence, enforcing a distinction between either 'seeking' or 'directing an action at' the PO participant requires subdividing the already fairly specific category of 'verbs for goal-directed hand motor actions' into yet more fine-grained subtypes of potential fillers. In addition, such an analysis implies that the pair in (5) constitutes a case of constructional homonymy: examples (a) and (b) are viewed as separate constructions not because of any differences in form, but because of their distinct meanings. At this point, however, one does not have to be a dyed-in-the-wool lumper to maintain that these two meanings are still much too similar to be treated as simply "unrelated”. Indeed Proost (2017: 25) locates examples like (5) within an "overlap area between the conative construction and the search construction". But since semantic overlap rules out homonymy, this undermines the semantic argument for treating (5.a) and (b) as separate constructions in the first place, and thus leaves either polysemy or vagueness to account for the observed meaning variation in (5).

A well-known approach that combines elements of vagueness and underspecification (pertaining to schematic 'central meanings' of grammatical constructions) with attention to semantically distinct but related subtypes (which elaborate this central meaning in different ways) is Goldberg's (1995) polysemy analysis of the English ditransitive construction. In the spirit of this analysis, semantic generalisations over groups of instantiating verbs like those in (4.a-c) could be taken to constitute different constructional senses (potentially with different subsenses in each case), whilst the hypothesised central meaning of the construction could remain fairly schematic (i. e. abstract enough to subsume both variants discussed in the preceding paragraph). How could the relevant meaning be characterised on this very general level? One possible generalisation over the expressions in (4) is that they all encode a scenario in which the subject participant aspires to get into some kind of contact with the PO participant. ${ }^{30}$ Accordingly, individual senses would highlight different aspects (or encode different manifestations) of this scenario of 'intended contact'. One possibility for this is that the verb characterises the subject's disposition towards the PO-participant more precisely (or at least provides some lexical categorisation of this dispo-

30 The Oxford English dictionary defines the primary sense of contact as the "state and condition of touching; the mutual relation of two bodies whose external surfaces touch each other" (p. 889). This is the kind of contact that is at stake in conative expressions. In figurative uses, the noun contact designates an abstract connection or relationship between two entities that is conceptualised in terms of physical touching. According to the OED, the entities involved in these kinds of relations "meet, come across, come into practical connexion with" each other. By characterising the meaning of the expressions in (4) in terms of 'intended contact', our description shares in the wealth of relations that can be construed as 'contact' scenarios in this sense. 
sition - cf. verlangen 'desire', sich sehnen 'yearn' and gieren 'crave' in 4.b). In such uses, the PO-participant does not need to be an entity, but can also be a state of affairs in which the subject participant desires to partake:

(6) Anschließend verriet Elton John, daß er ein Kind adoptieren will: "Ich sehne mich nach dem Glückserlebnis, ein Kind heranwachsen zu sehen.”

(Neue Kronen-Zeitung, 01.04.1995)

'Afterwards, Elton John revealed that the wants to adopt a child: "I yearn for the joyful experience of seeing a child grow up"'

Alternatively, the verb can also express an action that is meant to bring about the intended contact situation. The contact itself can either be concrete and physical, as with examples of the type in (4.c), or abstract and mental, as with the expressions in (4.a). Furthermore, the purpose of the action is often not just to establish some sort of contact per se (cf. 7.a), but rather to gain subsequent control of the goal entity (cf. 7.b):

(7) a. Hände streckten sich nach ihr aus, berührten sie.

'Hands reached out for her, touched her'

(Rheinzeitung, 19.12.2006)

b. Er griff nach dem Lenkrad und hielt die Spur.

'He grasped for the steering wheel and kept in lane'

(Hannoversche Allgemeine Zeitung, 13.07.2010)

Our target expression fragen nach is an example of the latter type: schematically, the purpose of asking is to obtain information, i.e. to establish mental contact with it in order to gain epistemic control of a certain proposition (cf. Langacker 2009: 131). In this manner, the different groups of verbal fillers exemplified in (4) could be analysed as different elaborations of the same constructional "central meaning" (or background frame) that are related by metonymy: they are about desiring a goal (a precondition for seeking to attain it), or about doing something in order to reach it (either in a concrete or an abstract sense), and often in order to obtain and control the intended entity thereafter.

On such an approach, semantic splitting only pertains to constructional (sub) senses, while the unified central meaning remains more abstract. In fact, the characterisation suggested above is even more lumping in spirit than Höllein's classification, since it also subsumes a meaning that he reserves for a separate category: that of the PO role 'ACCIPIENDUM' ('thing to be obtained'). On Höllein's account, POs with this meaning are restricted to the preposition $\mathrm{um}$. But the meaning 'intend to obtain' also arises with POs headed by nach. Our target verb fragen is a case in point:

(8) a. Die Frau fragt uns nach unserem Namen.

'The woman asks us for our names'

(Frankfurter Rundschau, 19.05.1999) 
b. Zunächst hatte der alkoholisierte Haupttäter nachts mit seinem Bekannten Giuseppe M. und dessen Freund aggressiv nach Zigaretten gefragt und dann eine Schlägerei mit den beiden angezettelt.

'At first, the inebriated chief offender had aggressively asked Guiseppe M. and his friend for cigarettes during nighttime together with his acquaintance, and then he had started a brawl with them'

(Nürnberger Nachrichten, 30.03.2012)

What is the difference between 'seeking' (as in 8.a) and 'intending to obtain' (as in 8.b)? Schematically, the meaning of nach $X$ fragen can be characterised as 'to perform a request, in order for something to be supplied' in both sentences. Note that the implication that the PO participant be 'supplied' is triggered by the verb fragen: here, 'contact' with the intended entity can only be established if the subject participant's request is granted by the addressee of the verb event, it cannot be established autonomously as in the case of other fillers such as suchen 'search', treten 'kick' or tauchen 'dive'. Arguably, then, fragen differs from other instantiating verbs like suchen, treten and tauchen in this respect, but what about the more specific contrast between 'supplying information about X' vs. 'supplying X' itself in (8)? Adopting a splitting perspective would lead to postulating two yet more fine-grained subsenses here, implying that one and the same verb (in the same reading) can instantiate two different constructional (sub)senses. Alternatively, the sense 'intend for somebody to supply something' could be seen as underspecified for such details, which would be left to infer (depending on semantic properties of the PO participant and the wider semantic context). Grammatically, there is indeed nothing to prevent an interpretation of (8.b) as a request for mere information about cigarettes, just like the request in (8.a) is for information about the addressee's names. Given the semantic context, such an interpretation is just not very likely. We conclude that there is little motivation for differentiating a 'seeking'-category (QUAESITUM) from an 'intend to obtain'-category (ACCIPIENDUM) of constructional meanings for nach-POs.

\subsubsection{Lumping problems}

Summing up the discussion so far, we have argued that splitting analyses on different levels which attempt to tease apart nach-constructions with a 'search' meaning from others with either a 'direct action at' (conative) or an 'intend to obtain' meaning (ACCIPIENDUM) run into problems because these supposedly distinct nach-constructions are both formally isomorphic and semantically non-homonymous (as indicated by the existence of 'overlap' cases). On the one hand, this would seem to favour a lumping analysis in terms of 'intended contact'. On the other hand, positing such highly schematic constructional meanings also raises new problems of its own - especially if 'getting into contact' with the PO participant is understood in so abstract a sense as to 
encompass notions like 'aspiring involvement in a state of affairs' (cf. (6)). Apart from relevant fillers of our target construction like verlangen 'desire', sich sehnen 'yearn', hungern 'hunger', dürsten 'thirst', gieren 'crave', lechzen 'lust', trachten 'strive' and the like, there are many other predicates with meanings in the relevant field of aspiration, intention and willingness that do not occur in the construction:

(9) a. (`nach) etw wollen/wünschen/beabsichtigen

'to want/wish/intend something'

b. auf $\left(/{ }^{\star}\right.$ nach $)$ etw hoffen/sich freuen/aus sein

'to hope for something, to look forward to something, to be after something'

In order to account for this, one could seek to identify semantic differences between the kinds of 'intended contact' scenarios that are covered by the nach-construction, and others that have a direct object in accusative case (9.a) or an aufPO instead (9.b). But this is just another way of saying that the schematic intended contact' generalisation (or this generalisation alone) is too abstract to do the job (i. e. drive syntactic argument realisation). Moreover, how can it account for the fact that some verbs with the relevant semantics can switch between the constructions in (9) and our target construction, whereas others do not? For instance, why are wünschen 'wish' and wollen 'want' ruled out in the nach-construction, but begehren 'covet' is not? And why are hoffen 'hope' and sich freuen 'look forward to' restricted to POs headed by auf, whereas fiebern 'feverishly look to' also occurs with nach?

(10) a. Warum haben wir Angst vor dem, was wir am meisten begehren?

'Why are we afraid of what we covet the most?'

(Süddeutsche Zeitung, 15.04.1997)

b. Doch die Narren, unter ihnen ECV-Sitzungspräsident Klaus Dietrich und der ECV-Vorsitzende Udo Kleemann rüttelten lautstark am Bauzaun, mit dem der Eingang abgesichert war, und begehrten nach Einlass.

'But the carnival revellers, among them ECV session chair Klaus Dietrich and ECV president Udo Kleemann, clamorously joggled the hoarding that secured the entrance and demanded entry'

(Rheinzeitung, 05.02.2005)

(11) a. Der Mittelfeldmann fiebert selbstredend auf einen Einsatz gegen Real. 'Of course, the midfielder is feverishly looking to take to the field against Real' (Die Rheinpfalz, 25.04.2012)

b. Der multimediale Mensch sitzt ständig angespannt vor irgendeinem Bildschirm oder fiebert nach einem neuen Kick.

'In the digital age, people are always stressed and attending to some kind of screen, or feverishly looking to experience a new thrill'

(Tages-Anzeiger, 11.06.1997) 
To repeat: the problem is not so much the existence of the two variants in these pairs. Instead, the question is why only some verbs (like begehren 'covet' and fiebern 'feverlishly look for') are compatible with both constructions, whereas many of their near synonyms cannot occur in the (b) sentences.

If contrasts like these were always semantically motivated, the relevant differences would have to be very subtle indeed. Boas (2010: 58) concludes from similar observations that "Goldberg's meaningful argument structure constructions are too powerful and thus inadequate for capturing the intricate syntactic and semantic differences exhibited by verbs closely related in meaning. Given her system of fusion of verbs with constructions, together with her system of constraints and metaphorical extensions, there does not appear to be a straightforward way of preventing her constructions from overgenerating unattested sentences". His argument is based on Goldberg's remarks on English ditransitive expressions like the following:

(12) a. She told Jo a fairy tale.

b. She wired Jo a message.

c. She quoted Jo a passage.

d. She gave Jo her thoughts in the subject.

(Goldberg 1995: 148)

Goldberg (1995) analyses such sentences as metaphorical extensions of the central sense of the ditransitive construction ('agent successfully causes recipient to receive patient') along the lines of the "conduit metaphor" (Reddy 1993). However, many verbs with meanings that are part of the target domain of this metaphor (COMMUNICATION) are not commonly used with ditransitive syntax:

(13) a. ${ }^{\star}$ Michael advised Collin the best area for running.

b. ${ }^{\star}$ She assured Joe her love.

c. * She informed Jo all the beers she had.

d. * She notified Jo her thoughts on the subject.

(Boas 2010: 57)

Boas (2010: 60) concludes from these observations that abstract constructional meanings like ' $\mathrm{X}$ successfully causes $\mathrm{Y}$ to receive $\mathrm{Z}$ ' (or 'X intends to get in contact with Y', to stay with our example) fail to specify the requisite amount of "detailed information that would allow a construction to fuse with a verb while at the same time preventing that same construction from fusing with a verb closely related in meaning”.

\subsubsection{Problems of combined approaches}

In fact, however, Boas' observation is not so much an argument against constructions that are too schematic to do the job, but rather against constructions as such 
doing the job, at least in the way envisioned by Goldberg (1995): on her account, "the mapping between semantics and syntax is done via constructions, not lexical entries” (Goldberg 1995: 28). Of course Goldberg is also aware of counterexamples to the semantic generalisations she proposes, ${ }^{31}$ which she seeks to accommodate through conflicting constraints imposed by "statistical pre-emption" of uses that would otherwise be expected (cf. Goldberg 2006: 93-102, Goldberg 2019: 74-94). However, the very fact that such unattested uses are characterised as "expected" 32 (in the absence of additional mechanisms) illustrates that her approach is essentially semantics-based: verbs can enter into independently existing constructions if they have compatible meanings, and the syntactic expression of their arguments is then handled by these constructions rather than projected from their lexical entries (i.e. item-specific valency properties). By contrast, the solution advocated by Boas is essentially a valency-based approach: he rejects Goldberg's central idea of "plugging" verbs into abstract constructional schemas ("there is no need for fusing lexical entries with abstract meaningful constructions”, Boas 2010: 75), and sees syntactic argument realisation as driven by item-specific valency properties instead. At the same time, these item-specific representations are envisioned as complex symbolic constructions - "miniconstructions" in Boas' (2003) terminology - that pair partially lexically filled syntactic templates with an associated semantic frame.

At first blush, Boas' approach has a number of advantages. Unattested usages like the expressions in (13) are avoided, since there is neither a productive abstract schema that would sanction them (on his account) nor an item-specific memorised miniconstruction with ditransitive syntax for advise, assure, inform and notify that would support them. Still, higher-order generalisations over individual miniconstructions are recognised in the model, and may be extracted on different levels of schematicity. For these higher order-constructions, compatible lexical units (LUs) are listed individually. Importantly, in cases/subtypes where the relevant association is truly semantic rather than lexically idiosyncratic in nature, so that really all LUs evoking a specific frame can be used in the construction, constraints on the verb slot may also include references to semantic frames instead of individual LUs evoking these frames. ${ }^{33}$ This avoids the opposite pitfall of having to posit "implausible verb senses" (i.e. lexical

31 cf. "[T]he ditransitive pattern is not completely productive within any generally defined class of verbs” (Goldberg 1995: 120).

32 cf. "That is, suppose that the first time a learner hears explain, she expects to hear it used in the double-object construction, but instead hears it used in the to-dative. At that moment, the probability of witnessing explain in a preemptive context is 1 , but only a single case has been witnessed" (Goldberg 2016: 385).

33 For instance, the list of LUs evoking the ditransitive construction includes not only individual LUs such as "signal.Communication" ('the sense of the verb signal that evokes the Communication frame'), but also underspecified placeholders like “v.Giving” ('all verbs that evoke the GIVING frame', Boas 2010: 71). 
entries) post hoc once the verb in question has been attested in an unusual/creative manner: if the verb can be interpreted in context in such a way as to match the semantic requirements of a particular constructional (sub)schema that is truly productive, it can be used in this construction without having to stipulate this unforeseen usage in advance (such as the 'forceful expulsion of air' interpretation of sneeze, which can be seen to match the verb slot restrictions of Goldberg's "caused motion construction" and thus gives the famous example of sneezing a napkin off the table).

Note, however, that in contrast to the claim that a process of "fusing" verbs with independently meaningful constructional schemas is not needed, such a mechanism actually is required in such cases in order to combine the benefits of both approaches. Saying that "all (verbal) LUs of the Giving frame can occur with ditransitive syntax" (p. 73) is logically equivalent to positing "abstract meaningful constructions" (p. 75), and fully abstract (i. e. lexically underspecified) constructions are indeed not rejected per se, but assumed to coexist with more specific units in the constructicon. But apart from the benefits, Boas' solution therefore also inherits the problems of Goldberg's approach: at least where such higher-level generalisations are concerned, Boas' proposal is in principle subject to the very criticisms that he levels against Goldberg. For instance, the oft-quoted example of donate, which is not conventionally used in the ditransitive construction in spite of its "compatible" semantics (cf. Wonnacott/ Newport/Tanenhaus 2008), is said to evoke the GIVING-frame in FrameNet, ${ }^{34}$ and would thus license a ditransitive usage that is in fact excluded. Nevertheless, a general difference between the two proposals is that Boas is much more reluctant to posit productive high-level abstractions than Goldberg and favours more concrete, lower-level schematisations where possible. So, in keeping with general tenets of usage-based linguistics, the orientation of Boas' approach is bottom-up, leading from miniconstructions to progressively more abstract schemas (where they are evidenced), and with no qualitative difference and neat separation between "lexical entries" and "constructional schemas", but an interconnected lattice of "constructions all the way down” (or rather up) the lexicon-syntax continuum (Goldberg 2006: 18). Above all, Boas' account points to how the seemingly irreconcilable, diametrically opposed premises of projectionist (lexical, valency-based) and constructionist (semantic, schema-based) theories of argument structure can be combined into an integrated model - specifically, the usage-based model of Langacker (2000). From this perspective, the very question of "valency or constructions?" appears misguided - it is a manifestation of what Langacker (1987: 28) calls the "exclusionary fallacy" 35 in the domain of verb argument structure.

34 Cf. https://framenet2.icsi.berkeley.edu/fnReports/data/frameIndex.xml?frame=Giving, last access: July 10, 2019).

35 "The gist of this fallacy is that one analysis, motivation, categorization, cause, function, or explanation for a linguistic phenomenon necessarily precludes another” (Langacker 1987:28). 
In recent years, many proponents of valency-based, projectionist theories of argument structure have begun to embrace the constructionist notion of inherently meaningful argument structure constructions, and have made very similar suggestions. For instance, unlike Boas, Herbst (2014) does not argue against Goldberg's central idea that verbs are "fused" with semantically compatible constructions, but suggests an additional principle governing this process that serves to ensure that verbs can only be fused with constructions whose form side corresponds to the verb's lexical valency pattern. This "valency realisation principle" states that "if a valency construction of a verb is fused with an argument structure construction and all of its participant roles are construed as argument roles, then the formal realisation of the argument structure construction (SYN) must coincide with the valency pattern of the valency construction" (Herbst 2014: 199). But what if it does not? Presumably, the principle is meant to block such uses, and for otherwise unexpected "gaps" like the non-ditransitive communication verbs in (13), the effect of this modified fusion process is the same as in Boas' approach - they are ruled out. Also, in contrast to a "pure” valency approach that is based solely on projection, Herbst's model has no problems with "creative" argument structures like the notorious sneezing-example: since no role of the valency construction of sneeze (which only specifies a subject) is in conflict with an argument role specification of the caused motion construction and the verb can be construed as compatible with its semantic predicate restrictions, there is nothing to prevent its use in this construction. But there are also cases that are problematic for this account. These are uses in which a verbal participant is expressed as an argument of a construction that specifies a different formal realisation for this element than the verb's lexical valency specification. An example is (10.b), nach etwas begehren 'to covet something'. The entity coveted is doubtlessly a participant in the verb's frame semantics, but it is canonically realised as a direct object in accusative case and not as a nach-PO. (14) gives some further examples of nach-POs with verbs that do not usually occur with them:

(14) a. Unsereins grübelte nach dem Sinn des Lebens, sie kannten die Antwort: „42”.

'People like us mused about the meaning of life, they knew the answer: "42"” (die tageszeitung, 09.06.2005)

b. „Es gab überhaupt keine Anzeichen. Und Streit gabs auch keinen”, rätselt der Betriebsschlosser nach einem Motiv.

“"There had been no signs whatsoever, and no quarrelling”, the company locksmith brooded in search of a motive' (die tageszeitung, 29.06.1990)

c. Seit Jahren eruiert er in Archiven nach Unterlagen aus dieser Zeit und unterhält Kontakte mit Forschern im In- und Ausland.

'For years, he has been checking up on documents from this period in archives and building contacts with researchers at home and abroad' (Rheinzeitung, 19.04.2001) 
Expressing the object of contemplation in the form of a nach-PO is unusual for the verbs in (14) - the most common object coding in two-place uses of rätseln 'rack one's brain' is a wh-complement clause, and a nominal accusative object with eruieren 'find out'. PO uses are common only with grübeln 'brood' and rätseln, but virtually always involve the preposition $\ddot{u b e r} .^{36}$ Similar cases in which one would expect a particular verb-construction combination to be pre-empted by a much more entrenched constructional competitor are also found in other PO-constructions:

Der Angeklagte habe die tödlichen Folgen billigend in Kauf genommen, um vor der Polizei zu entkommen und andere Straftaten zu verdecken.

'The defendant was said to have wilfully endorsed the fatal consequences in order to escape from the police and cover up other offenses'

(Hannoversche Allgemeine Zeitung, 21.09.2018)

Here, a dative object would be much more common than the prepositional complement with vor. From a lexical valency perspective, such uses are unexpected. So why do we get them nevertheless? In the case of entkommen 'escape', the reason is presumably analogical pressure from near synonyms with the meaning 'to flee' (fliehen 'flee', flüchten 'flee', abhauen 'do a runner' and many more) that take a vor-PO, which is generally common in constructions that designate responses to a threat (Zeschel 2019). This would mean that entkommen can be used in the prepositional construction in (15) because it is semantically attracted to it, in spite of its putative lexical valency specification of the evaded entity as dative-marked. A similar account could be offered for the nach-PO uses of grübeln, rätseln and eruieren in (14). While comparably general, semantically 'light' verbs of cogitation such as denken and sich überlegen 'think' are not found in the construction, these verbs may be drawn to it because of their more specific meanings: among others, the construction is compatible with verbs that designate efforts undertaken in order to get into contact with the intended entity. And this is what these verbs do within their larger field, each in its own way: grübeln is morphologically iterative, implying prolonged preoccupation with a subject matter ('persistent thinking'), rätseln is not only iterative, but also implies difficulty

36 In a random sample of 100 attestations of grübeln, rätseln and eruieren in the German reference corpus DeReKo, $62 \%$ (grübeln), $64 \%$ (rätseln) and 33\% (eruieren) of the sentences had two arguments in active finite clauses. With grübeln, the object in these sentences was typically prepositional (45\%), but only one single occurrence was headed by nach, all remaining instances had über. Two-place uses of rätseln most commonly involved wh-complement clauses, but prepositional objects were frequent, too (39\%). Apart from two sentences with um, all remaining POs with rätseln had the preposition über, i. e. there was no instance of a nach-PO in the data. The verb eruieren typically occured with a nominal accusative object in two-argument uses, and there was no instance with a prepositional object in the sample at all. 
('hard thinking'), and eruieren designates an act of particularly thorough deliberation ('deep thinking'). ${ }^{37}$

To conclude, lexical and constructional approaches to argument structure have complementary strengths and weaknesses, and both mechanisms - lexical selection and categorisation by semantic schema - have a part to play in the argument structure puzzle. While the theoretical details of how these two perspectives can be combined do not concern us here, the discussion nevertheless has a direct bearing on the granularity of constructional descriptions: in some way, the conflicting demands of capturing the general, but attending to the particular must be reconciled. Before we discuss practical implications of this observation for constructicography, we first consider similar issues regarding the formal side of verb argument structure constructions.

\subsection{Granularity of form}

What can we say about the formal specifications of the 'intended contact' construction discussed in the preceding section? Up to now, we have considered instances with two arguments, a subject and a prepositional object, as illustrated by the examples in (4), repeated here as (16):

(16) a. nach etw fragen, sich nach etw erkundigen

'to ask about something', 'to enquire about something'

b. nach etw verlangen, sich nach etw sehnen, nach etw gieren

'to desire for something', 'to yearn for something', 'to crave for something'

c. nach etw greifen, nach etw fühlen, nach etw tasten

'to grasp for something', 'to feel for something', 'to grope for something'

But this is only the case in certain realisations. For one, there are several possibilities for the first argument to remain unexpressed, so that only the prepositional argument is realised:

37 Since semantically more general verbs like denken are also much more frequent, it seems possible to consider an alternative, non-semantic explanation here: maybe less commonly used verbs generally lend themselves to syntactically atypical, creative uses more easily than high frequency items. But this would not explain why other verbs of cogitation that are also semantically specialised vis-a-vis the more general denken 'think', albeit not in the specific way required by the nach-construction, do not occur in the construction either. This is true of a number of semantically different verbs like mutmaßen 'conjecture', abwägen 'weigh up' and schlussfolgern 'infer', each of which is more specific in meaning than denken in its own way and also less frequent in usage. Nevertheless, in contrast to grübeln, rätseln and eruieren, none of these verbs specifically profiles the amount of cognitive effort expended, and none of them occurs in the nach-construction. 
(17) a. Den entscheidenden Hinweis bekam er von einem ehemaligen Juso-Kollegen der Politikerin: Frag mal nach ihrem Lebenslauf, sagte der Informant. 'The crucial lead came from a former Juso-colleague of the politician: Ask for her CV, the informant said' (Focus, 30.07.2016)

b. Für die Finanzen hatte sich in Berlin zuvor niemand sonderlich interessiert nach Geld wurde nicht gefragt, Geld wurde einfach ausgegeben.

'Nobody had been particularly interested in public finances in Berlin before - there were no questions asked about money, it was simply being spent' (taz, 07.04.2001)

c. Er hätte gar nicht gewusst, dass am Wochenende auf dem Speedway ein Rennen stattfinde, so der nach dem Weg gefragte Polizist.

'He had not been aware that there was a race on the speedway at the weekend, declared the policeman asked for the way' (St. Galler Tagblatt, 23.09.2000)

Are we in fact dealing with the same argument structure construction if certain verbal participants are unexpressed, or mapped to different grammatical relations in each case? How constructionist approaches to argument structure can handle phenomena like passive and deverbal adjectivalisation is a matter of some debate (cf. Müller \& Wechsler 2014; Welke 2015). Even if these theoretical discussions do not concern us here, examples like (17) show that it is important to clarify what a given description is meant to cover: which elements of the described construction are deemed necessary, and under which circumstances? And which kinds of interactions with which other types of grammatical constructions are envisioned? In the remainder of this section, we will not discuss specific solutions to these issues and their respective theoretical implications, but merely showcase some of the form-related problems that arise in identifying constructional instances in a given dataset. How they are dealt with in our own resource is summarised in section 4.

So which arguments must be part of the constructional description? In the case of PO constructions, it is clear that at least the PO argument must be present in order for something to count as a potential instance of the targeted construction(s). But apart from that, variability in argument realisation does not only pertain to the subject argument:

(18) a. Ich fragte nach Ihrem persönlichen Verhältnis.

'I asked for their personal relationship'

(die tageszeitung, 16.09.1992)

b. Jutta Göricke fragte ihn nach den Ergebnissen.

'Jutta Göricke asked him about the results'

(Süddeutsche Zeitung, 05.03.2005) 


\section{c. Wir fragen uns nach dem Warum und bekommen keine Antwort. \\ 'We ask each other/wonder why and do not get an answer' \\ (Protokoll der Sitzung des Parlaments Thüringer Landtag am 03.05.2007)}

Are the examples in (18) instances of one and the same argument structure construction? At first blush, clearly no: (18.a) is intransitive, (18.b) is transitive, and (18.c) is ambiguous between a transitive interpretation ('we ask each other') and a reflexive one ('we wonder') in which the pronoun is not an accusative object, but part of the verb form. Welke (2015: 102) argues that such structural differences outweigh any semantic commonalities: "Wie traditionell in Bezug auf Wörter, so gilt auch in Bezug auf Konstruktionen, dass über die Identität einer Konstruktion die Form entscheidet. Ausnahme ist Homonymie" ('As in the case of words, the identity of a construction is determined by its form, with the exception of homonymy'). But maybe one could posit a more general construction subsuming (18.a) to (c), in which the possible extra argument is optional? Goldberg (2006: 22) considers a similar solution for active and passive ditransitives which would "define the ditransitive construction more abstractly such that it would not specify that there are two objects overtly realized". In our case, an argument against such a solution is (19):

(19) a. Sie erklärte den Kindern die Bedeutung und die Tradition der Kräuter und Blumen und befragte sie nach den Namen.

'She explained the significance and the tradition of the herbs and the flowers to the children and questioned them about the names'

(Straubinger Tagblatt, 11.08.2016)

b. * Sie befragte nach den Namen.

The construction in (19) has the same form and the same meaning as the construction in (18.b), but with fragen's near synonym befragen 'question', the accusative object is obligatory. Conversely, sich erkundigen 'to enquire', another near synonym of fragen, is only found in reflexive uses:

(20) a. Wir erkundigten uns nach dem Stand der Dinge.

'We enquired about the state of affairs'

(Neue Kronen-Ztg., 12.01.1999)

b. *Wir erkundigten nach dem Stand der Dinge.

c. *Wir erkundigten euch nach dem Stand der Dinge.

Regardless of whether such contrasts are attributed to semantic or syntactic (valency) properties of these verbs, the fact that an accusative object is required for befragen 'question' but ruled out for erkundigen 'enquire' indicates that at least two separate constructions (or formal variants within a network of related constructions) are required here. And what about the reflexive uns 'each other' in (18.c): does it mark a further reflexive (sub)construction, or is it part of a separate reflexive verb? If the 
mental rather than communicative meaning of sich fragen and sich erkundigen (literally 'to en-knowledge oneself', i. e. to make oneself knowledgeable) is attributed to a separate construction, we are dealing with one and the same verb fragen in (18.a) to (c). If, on the other hand, this meaning is attributed to a separate verb sich fragen, we are dealing with the same intransitive construction in (18.a) and (c). At any rate, the unclear status of the pronoun in (18.c) illustrates that it is not always trivial to ascertain just how many arguments there are in a given construct to begin with. In other cases, additional arguments are neither part of the (atomic) verb's lexical valency specification nor contributed by the PO construction:

(21) a. Ich habe ihm Löcher in den Bauch gefragt nach Ausbildungen, Programmen und Werbung.

'I pestered him with questions about training courses, programms and ads' (Frankfurter Neue Presse, 13.01.2010)

b. An den zwei großzügig gestalteten Bars gab es eine reichhaltige Auswahl und niemand musste lange warten. Da hatte man aus den Erfahrungen der vergangenen Jahre gelernt, als sich die Gäste nach einem Glas Wasser die Beine in den Bauch standen.

'At the two generously designed bars, a wide selection was offered, and nobody had to wait long. They had learned from their experience in the past years when the guests cooled their heels waiting for a glass of water' (Nordkurier, 02.09.2013)

c. Ich suche mir schon seit 3 Wochen die Finger wund nach der Kauf-DVD von "Legends of the storm".

'For three weeks, I have been searching my fingers to the bone for the sellthrough DVD of "Legends of the strom",

(Wikipedia; Diskussion: Legends of the Storm, 29.10.2011)

The examples in (21) combine formal and semantic properties of our target construction with those of the resultative construction (Müller 2002, Boas 2003) as well as the possessive dative construction (von Polenz 1969: 159-167; Wegener 1985: 111-112). ${ }^{38}$ In the case of (21.a) and (b), the additional arguments ihm/sich, Löcher/die Beine and in den Bauch form idiomatic multiword expressions together with the verbs fragen and stehen that enter into the PO-construction as complex predicates, where they combine with its subject and PO arguments. (21.c) illustrates that simplex verbs which commonly occur in our target construction (like suchen 'search') are also found in such structures, without comparably clear indications for a lexicalised status of the

38 Complex interactions like these can lead to uncertainty and variation: in DeReKo, both jemanden (accusative) Löcher in den Bauch fragen and jemandem (dative) Löcher in den Bauch fragen are attested. In the former variant, the adressee argument receives its case from the verb (jemanden etwas fragen), in the latter version, it comes from the possessive dative construction. 
complex predicate that they form. Again, such uses must not only be dealt with theoretically, but also require descriptive approaches to specify what is within and what is outside the scope of their accounts (and how and where such interactions should be handled within the constructional inventory of a language).

Of course granularity issues do not only concern the number of realised arguments, but also their concrete formal specifications (be they lexical or categorical). Consider again the examples in (1), repeated here as (22):

(22) a. Wir fragten Jugendliche nach ihrer Meinung.

'We asked youths about their opinion'

(Berliner Zeitung, 16.06.2003)

b. Wir fragten einige Schüler über ihre Meinung.

'We asked several pupils about their opinion'

(Rheinzeitung, 10.12.2013)

c. Als neuer Kapitän hat er Köpke sehr oft um seine Meinung gefragt.

'As the new skipper, he has often asked Köpke about his opinion'

(Nürnberger Nachrichten, 19.05.2001)

d. Ich sprach Leute in Cafés und auf der Strasse an und fragte sie zu ihrer

Meinung.

'I approached people in cafés and in the street and asked them about their

opinion'

(St. Galler Tagblatt, 14.12.2009)

With Höllein (2019), we assume that PO-constructions with the four prepositions nach, über, um and $z u$ are (families of) meaningful argument structure constructions in the construction grammar sense that are both formally and semantically distinct. Nevertheless, the examples in (22) illustrate that there also exist points of overlap and contact between these constructions that point to some substantial similarities (at least among particular instances or subtypes of these constructions). Note that in contrast to the problematic separation of 'intended contact' and conative nach-constructions discussed in the preceding section, acknowledging such overlap cases does not undermine the separation of these constructions per se, since they are still formally distinct (in virtue of their different prepositional construction markers) and hence no candidates for homonymy. Since constructionist approaches also eschew synonymy, however, the assumption would rather be that the apparent overlap is actually an artefact of handpicked minimum contrast sets like (22): looking at more data, one would expect to find relevant differences between these constructions, however subtle they may be in places (cf. Uhrig 2015 for a critical assessment of this assumption). But saying that two or more elements are only distinguished on some more specific semantic sublevel entails that there is a higher, more schematic level at which they can be seen as undifferentiated. So could it also be feasible to subsume these overlap cases to a schematic overarching construction that generalises over 
them, one with a schematic prepositional slot instead? ${ }^{39}$ In order to account for variation in verb particle placement in English (e.g. pick up the book vs. pick the book up), Capelle (2006: 18) proposes the concept of "allostructions", defined as "variant structural realizations of a construction that is left partially underspecified" for some aspect of its form. The schematic construction that is elaborated by these different allostructions in different ways is referred to as a "constructeme". So, in the terminology of Capelle, should our description only comprise PO constructions with the preposition nach, or should it be extended to other allostructions of an assumed 'intended contact' constructeme? And is it possible to give principled reasons for preferring one possible level of description over others? We leave this question for the discussion in section 4. For the time being, note that the concept of allostructions may also be useful in order to capture other kinds of formal variation, for instance argument mappings to different grammatical relations:

(23) a. Er dürstet nach kluger Gesellschaft.

'He thirsts for intelligent company'

(Der Spiegel, 01.08.2015)

b. Es dürstet ihn nach Authentizität.

'He thirsts for authenticity'

(Die Welt, 04.10.2002)

c. Ihn dürstet nach Ruhm.

'He thirsts for glory'

(Süddeutsche Zeitung, 18.12.2004)

d. Ihm dürstet nach internationalen Erfolgen.

'He thirsts for international triumphs'

(Neue Zürcher Zeitung, 30.10.2004)

(23.a) has the EXPERIENCER argument of dürsten 'thirst' as a subject, in (b) and (c) it is realised as an accusative object (either with or without impersonal es 'it' in subject function), and in (d) it is a dative. Only very few verbs found in the 'intended contact' construction exhibit this kind of variation. But for those that do, how should this kind of structural variation be accommodated? Do such examples necessitate the postulation of four separate (sub)constructions with identical meaning, but distinct form? Judging from the mapping of the verb's EXPERIENCER participant to different syntactic surface forms, the answer would be yes. But these constructions are also clearly related on a level that a convincing description should not fail to capture. A proper

39 It is clear that the slot of the preposition would not be truly open in such a schema, since many prepositions cannot head a PO of the relevant semantic type (cf. ${ }^{*}$ jmdn an/auf/aus/bei/in/von/vor seine(r) Meinung fragen). But this is nothing unusual within a constructionist approach. Many constructions are characterised by a limited type frequency of lexical fillers of a particular slot and do not permit just any element of a given syntactic category in this position. 
description should therefore reflect both properties: it should be able to represent potentially fine-grained structural variability in connection with specific fillers, but it should also clearly indicate that (and how) the postulated variants are connected.

\section{Towards a constructicon}

The issues raised in sections 2 and 3 give rise to a number of desiderata for the treatment of German prepositional objects in a construction-based reference work. In what follows, we introduce an approach to the description of these constructions currently developed in the project Verben und Argumentstrukturen ('Verbs and argument structures') at the Leibniz Institute for the German Language in Mannheim. In section 4.1, we discuss different general features of the proposed descriptions under the headings Format and access (4.1.1), Grouping strategy (4.1.2), Levels of description (4.1.3), and Content and Navigation (4.1.4). In section 4.2, we illustrate an application of this approach to German nach-PO constructions and discuss how the problems raised in section 3 are addressed in this solution.

\subsection{General design features}

\subsubsection{Format and access}

Ideally, constructica should be implemented in a digital (usually web-based) resource with a flexible access structure. This is to say that it should be possible to look up and filter constructional descriptions according to (combinations of) lexical, structural and semantic criteria.

Lexically, a constructicon of PO-patterns should permit searches for both prepositions and verbs. In our case, queries for PO-prepositions directly lead to the so-called top level descriptions provided for these items (cf. 4.1.3 below). Queries for verbs produce lists of PO-constructions in which these verbs are attested in the database. As Herbst (2017: 176) notes, the possibility of such lexically-based queries constitutes an important advantage over traditional reference grammars, since contents can be accessed with little to no background knowledge of relevant grammatical terminology. In connection with collocation phenomena and their possible semantic diffusion within and across constructions, it may furthermore be interesting to index patterns that are attested with particular lexical complements of the preposition (i.e. heads of the embedded nominal).

Apart from lexical fillers of different constructional slots, it should also be possible to search the database for constructions exhibiting (combinations of) specific structural properties. For instance, it should be possible to look up which other verbs 
apart from dürsten 'thirst' in (23) can appear in subjectless two-place uses with an accusative or dative argument apart from the PO. Importantly, it should be possible to combine structural and lexical search criteria in such queries (cf. our remarks on the search functionality in E-VALBU in section 2.2).

In addition, it would be interesting to provide an onomasiological access strategy to the data that permits searches for constructions that encode particular meanings. Minimally, the resource can implement a reverse search functionality that permits users to select a category from the list of postulated meanings and then displays the associated construction(s). For this to be of actual use in practice, it is of course essential that the designations on this list are both concrete enough to capture the gist of a given (family of) constructional meaning(s) and general enough to be understandable on their own (i. e. as a decontextualised name on a list, so that the user is not at a loss as to what a given category name may stand for). A more advanced functionality would also permit searches for semantic categories that group individual constructional meanings together on some higher level, thus allowing the user to discover constructions with meanings that are similar in some respect, but different in others (as would be expected on the assumption that structurally different constructions are never fully synonymous). For instance, what we have identified as the INTENDED CONTACT meaning of nach-POs is analysed as a purposive sense in Kiss et al. (2016), which is in turn analysed as a subtype of conditional meaning by the authors and grouped together with other kinds of conditional preposition meanings. For such a systematisation, constructions could be tagged for fairly general semantic features such as e.g. "causal”, "scalar”, "temporal” and the like (where appropriate), permitting the user to retrieve lists of all elements with a specific tag (or tag combination). Such a functionality could be appealing especially in didactic contexts, i. e. for learners of German as a foreign language.

Different access strategies produce different kinds of results. Searching for verbs, nominal complements of the PO-preposition or schematic structural templates such as "two-argument pattern with (i) PO and (ii) dative complement" produces lists of constructions whose individual entries are linked from the results display. By contrast, searching for a PO preposition or a specific constructional meaning directly leads to the individual descriptions associated with these elements.

\subsubsection{Grouping strategy}

In the passage quoted in section 3.2, Welke (2015: 102) argues that the identity of a construction is ultimately determined by its form and not by its meaning. This implies that e. g. each of the different sentences with dürsten 'thirst' in (23), er/ihn/ihm dürstet nach etwas, instantiates a separate prepositional argument structure construction. Alternatively, the three variants could be analysed as allostructions of an underlying constructeme (i.e. instances of some more general schema), which would strengthen 
the case for their similarity (by lumping their forms) rather than emphasise their differences (by splitting their forms). Similar issues arise in connection with other kinds of formal variation, too. Should nach etwas suchen 'to search for something' and etwas nach etwas durchsuchen 'to search something for something' be treated as separate constructions? On the one hand, an intransitive argument structure clearly is different from a transitive one, and not just structurally - also the number of realised frame elements is different. But the frame that is evoked in both cases is nevertheless the same. And there are also substantial formal similarities between these two expressions. Hence, being PO expressions with the same preposition that also evoke the same general scenario, there are also good reasons for treating these expressions as primarily alike and not as primarily different.

Similar cases of transitivity variation (without a change of overall semantic frame) are by no means unusual. However, the semantic role of the object argument in the transitve variants of such pairs depends on the particular construction in question. In the case of etwas nach etwas durchsuchen, the object encodes the PATIENT (i.e. the entity or domain that is being searched for the PO participant), whereas the role of the subject is the same as in the intransitive variant with suchen. In the caused motion construction (Goldberg 1995: 152-179), by contrast, the object has the same role as the subject argument in the intransitive variant of the construction (a „mover (theme)" according to Goldberg 1995: 207). Do such variants likewise qualify as "allostructions”? Capelle (2006: 25) suggests that ,the term 'allostructions' can prove to be useful to refer to any kind of formal variants". Since the abstract underlying constructions ("constructemes") behind these variants must still cohere on certain grounds, this implies that the underspecified schema that generalises over them must still have an identical semantics (Capelle speaks of "a level of representation at which the two versions are perceived to be semantically identical”, p. 13). But in transitivity variants like the above examples, the meaning remains identical only on a schematic level: as their names imply, both intransitive motion and caused motion constructions are motion constructions. Clearly, however, the meaning ' $\mathrm{X}$ moves to $\mathrm{Y}$ ' also differs from the meaning ' $\mathrm{Z}$ causes $\mathrm{X}$ to move to $\mathrm{Y}$ ' in a certain way. So are we dealing with the same or with two different meanings? Whatever one's answer, we are back at the question of taking a lumping or splitting approach to semantic analysis.

Ultimately, the question to be asked is: what is gained by either lumping or splitting such expressions? Or, more precisely, which kind of treatment is beneficial for a given purpose? In our case, the purpose is to compile a reference constructicon of German prepositional object constructions that seeks to document the usage and systematic meaningfulness of these constructions (which has been disputed in the past). Since postulating a plethora of formally independent entries obscures the larger picture of their semantic commonalities, we accord primacy to meaning rather than to form (at least in connection with the aforementioned variants). Note that this is not to say that the constructions thus delineated are defined with regard to meaning only (which would be the opposite extreme). For instance, such different expressions 
as the noun Gier ('greed'), the adjective versessen 'keen (on something)' and the sentential idiom jemandem läuft das Wasser im Mund zusammen 'someone's mouth is watering' also have meanings relating to 'intended contact', but our description only applies to a particular structural kind of such expressions - verb argument structure constructions with a prepositional CE (“construction element”). Furthermore, prepositional verb argument structure constructions that have the relevant schematic meaning, but nevertheless involve a different PO preposition than nach (such as auf etwas brennen 'to be be keen on something', auf etwas hoffen 'to hope for something', auf etwas hinarbeiten 'to work towards something' etc.) are still treated in separate entries in the resource, and any relations between such individual entries are only investigated in a second step (and independent type of article/description). Hence, we postulate a primacy of semantic grouping criteria only within a certain circumscribed range of formal restrictions, and both kinds of properties are seen as necessary elements of the definition and differentiation of our basic units of description from other constructions in the system.

Summing up, the question is not whether or not a relevant formal contrast with respect to argument realisation should be covered, but where. In our approach, formal properties like e.g. the existence of transitivity or case variations are covered within the entries for constructional categories that share a certain schematic meaning. This is similar to Goldberg and Jackendoff's (2004) analysis of English intransitive and transitive resultative constructions as members of the same overarching "family" of resultative constructions in general. As part of our description of associated instances, constructional variants with additional arguments are then specified for the semantic role of the extra argument, and indexed for instantiating predicates in the database. Likewise, allostructions for particular formal realisations of a given argument are also marked for predicates that exhibit this kind of variation.

\subsubsection{Levels of description}

In section 3, we have argued for a multi-layered description that combines lumping and splitting perspectives on the data. This implies that our descriptions should be organised into a hierarchy. We postulate three different levels of description within this hierarchy: top-level descriptions, family-level descriptions, and construction-level descriptions. As a fourth type of element, we posit overlap descriptions, which cut across both individual categories and separate hierarchies for different PO-prepositions.

Top-level descriptions systematise the semantic usage spectrum of constructions with a given PO-preposition at large. Below that, descriptions of individual constructions with this preposition are provided. These constructions can be characterised on different levels of abstraction, too. A schematic description is provided on the intermediate of our three levels, which we refer to as the family-level description. Family-level descriptions capture the most inclusive semantic generalisations that 
can be formulated over a given subset of the data. Such descriptions specify what all members of a given family have in common, and how individual members are related. They do not in themselves provide a sufficient characterisation of individual members (i.e. constructions). The second important component of such a characterisation is provided on the level of individual family members, each of which elaborates the shared schematic family meaning in a specific way. These subtypes or individual members of a family are described on the third and least abstract level, the construction-level description.

It is important to stress that only three different types of levels are posited, but not a fixed number that is identical for each and every construction in the resource. Allowances for additional levels of generalisation must be made, since semantically coherent construction families may branch into further subfamilies above the level of individual constructional descriptions. How many levels are to be distinguished for a given family of constructions is an analytical decision that has to be justified on a case by case basis. Diagrammatically, our approach can be illustrated as follows:

Figure 1: Levels of description: top-level (T), family-level (F), construction-level (C)

The hypothetical example in figure 1 provides a partial view of a visualisation of the semantic spectrum of all constructions with a given PO preposition. The diagram shows that three semantically distinct construction families $F_{1}$ to $F_{3}$ are postulated for this preposition (top-level description). Details are only shown for family $F_{1}$, for which five separate family members $C_{1}$ to $C_{5}$ are posited (family-level description). In contrast to the family categories $F_{1}$ to $F_{3}$, these meanings are on the one hand distin- 
guishable and hence separated, but on the other hand also connected, since they all relate to the same overarching family meaning $F_{1}$. Hence, the meaning of an individual construction like $C_{1}$ is composed of the genus proximum of its superordinate family meaning $F_{1}$ and its differentia specifica vis-à-vis the fellow family members $C_{2}$ to $C_{5}$. This composite meaning is characterised in the construction-level description. Below this level, no genuinely independent constructional meanings are recognised. In case there are further relevant distinctions to be made (even though they do not warrant positing an independent constructional meaning), semantic variants of a construction can be postulated. In figure 1 , such variants are only shown for construction $C_{1}\left(V_{1}\right.$ to $V_{3}$ ). Descriptions of such variants are integrated into the relevant construction-level description.

Apart from the nested sets of types $F, C$, and $V$, figure 1 also indicates two relations between categories in the form of connecting lines between constructions $C_{1}$ and $C_{4}$ on the one hand and $C_{1}$ and $C_{5}$ on the other. Such links point to the existence of overlap cases that combine properties of two or more categories and cannot be clearly assigned to either of these. Such expressions are illustrated and discussed in separate overlap descriptions.

\subsubsection{Content and navigation}

Displayed contents vary according to the currently selected level of description. Users can browse between descriptions by clicking on elements on different levels of description in interactive visualisations of the type exemplified in figure 1.

Top-level descriptions do not characterise individual constructions. Instead, they provide an overview of the total range of independent meanings that are postulated for a given PO-preposition. Even though the different families of PO-constructions $F_{1}$ to $F_{n}$ possess clearly differentiated meanings, it is usually possible to relate them to different adverbial source structures with the preposition in question, and semantic relations between these in turn can typically be reconstructed (cf. section 4.2 for an example). Hence, top-level descriptions provide links to individual family-level decriptions and comment on their relations to semantically more substantive uses of the preposition in question. Quantitatively, visualisations like figure 1 indicate the relative frequency of different families in the dataset, which is reflected by the proportions of elements $F_{1}$ to $F_{n}$ in the diagram.

By clicking on a given family $F$, users are taken to the family-level description of this category. Here, individual subtypes/members of this family are listed. Usually, there exist motivated semantic relations between the different subtypes of a family. Such relations are not discussed in individual construction-level descriptions, but in the overarching family-level description. Quantitatively, diagrams like figure 1 again provide information on the relevative frequencies of all postulated subtypes (i.e. individual constructions with a given PO-preposition). 
Clicking on a given construction $C$ opens the construction-level description of this element. Construction-level descriptions are the key component of the resource. They comprise the following elements (cf. Engelberg 2019):

- Qualitative characterisations of constructional form and meaning

- Information on associated allostructions and semantic variants

- A list of instantiating predicates in the database

- Linked sample sentences for these predicates in the construction

- A verbal collexeme analysis (cf. Stefanwitsch/Gries 2003) of the construction in the database ${ }^{40}$

- A list of associated overlap descriptions (where applicable)

- Pointers to treatments of this construction in the literature (where applicable)

Insofar as overlaps to other constructions are posited, users can click on their visualisations in the diagram to open a separate overlap description. Such descriptions contain relevant sample sentences from the database alongside a brief discussion of the properties that mark these sentences as overlap expressions. Note that overlaps within and between constructions with a specific PO-preposition are of different kinds: within the network of a given PO-preposition, overlap cases indicate ambiguity, since there are conflicting indications as to where these instances should be assigned within the given network. Such expressions resemble clear instances of both categories (or of each of the categories, if more than two are involved) both formally and semantically. We refer to such cases as ambiguity overlaps. By contrast, in similarities across networks (not shown in figure 1), as in the different PO-expressions with fragen in example (1), no ambiguity is involved: any given token in the dataset has one specific preposition, and hence belongs into this formally distinguished family. Such overlap cases only resemble one another semantically, i.e. are candidates for (near) synonymy. We refer to them as synonymy overlaps. While it is clear that no two PO-prepositions (some of which comprise many different families) are completely synonymous altogether, i.e. fully interchangeable in every context, the existence of more narrowly circumscribed synonymous subtypes is an empirical question that should not be ruled out in principle (for a different view, cf. Höllein 2019). Even within a given family of constructions, such synonymy overlaps are usually only partial. To illustrate, there are two similar German predicative constructions with the prepositions mit (Hilpert 2009) and in (Zeschel 2018):

(24) a. Mit Bushido (64.) und Kay One (95.) schafften es nur noch zwei Vertreter des Gangsta-Stils in die Top100.

'In the person of Bushido (64 $\left.4^{\text {th }}\right)$ and Kay One ( $\left.95^{\text {th }}\right)$, only two exponents of the Gangsta-style made into the top 100'

(Mannheimer Morgen, 05.01.2013)

40 (Herbst 2017: 180) refers to this kind of information as the "collostructicon in the constructicon". 
b. In Bushido hat er einen ergebenen Fan.

'In the person of Bushido, he has a devout follower'

(Frankfurter Allgemeine Zeitung, 06.07.2005)

However, the construction with mit is not only more frequent, but also has a wider range of application than its competitor with in (Zeschel 2018). For instance, while instances like (24), which identify named entities (notably people) as instances of a specific category (Bushido - exponent of the Gangsta style, Bushido - fan), work fine with both prepositions, constructional subtypes with mit that identify quantifiable entities with a particular value are ruled out with in:

(25) a. Der Zinssatz blieb mit 5,25\% unverändert.

'With $5.25 \%$, the interest rate remained unchanged'

(Hilpert 2009: 47)

b. *Der Zinssatz blieb in 5,25 \% unverändert.

Hence, we hold that the (partial) synonymy question can only be answered once a truly comprehensive and suitably detailed set of descriptions is available for each PO preposition and candidates for (near) synonymy can be contrasted on the basis of sufficient data. It follows that while we do not rule out the existence of low-level cross-PO schematisations a priori, we do not approach cases of PO-preposition variation like nach/um/über/zu etwas fragen top-down as allostructions of an overarching constructeme from the outset, but reserve descriptions of any such cross-cutting schematisations to synonymy overlap descriptions for the time being. Coming back to the question raised in section 3.2, our solution is therefore to provide descriptions of both PO-specific schemas and descriptions of more abstract schemas with an underspecified prepositional slot (insofar as they are evidenced). Taking a bottom-up perspective, however, primacy is accorded to PO-specific descriptions, whereas any possible cross-cutting schematisations are dealt with in separate overlap descriptions.

\subsection{An illustration}

Let us now consider how this approach accommodates the various problems raised in connection with the 'intended contact' construction discussed in section 3. Our presentation will not provide the actual data and descriptions supplied in the resource, but merely indicate what kind of information is specified where, and how.

The top-level description of German nach-POs provides an overview of the different families of these constructions that are distinguished in our analysis. In this, it sets the INTENDED CONTACT family apart from other higher-order categories such as the uses that Höllein (2019) identifies as POs with the semantic role KRITERIUM (here designated as the family of ACCORDANCE nach-PO constructions). The top-level description furthermore discusses relations beween the meanings of these PO-con- 
structions and semantically more substantive uses of nach as found in different kinds of adverbial constructions. In our example, INTENDED CONTACT expressions like nach etwas tauchen 'to dive for something' share the allative meaning component of intransitive motion expressions with nach like nach unten tauchen 'to dive down'. By contrast, ACCORDANCE uses like nach Leistung bezahlen 'to pay according to performance' show greater similarities to temporal uses like nach Fertigstellung bezahlen 'to pay upon completion'.

The family-level description of the construction specifies the number and designations of individual members of this family. Three separate meanings are distinguished: INTENDED CONTACT|TOUCHING, INTENDED CONTACT|OBTAINING, and INTENDED CONTACT|PARTAKING. The TOUCHING subtype covers conative expressions like nach etwas schlagen 'to hit at something'. Here, the purpose of the action is to establish physical contact with the PO participant. In the oBTAINING subtype, the subject referent does not only attempt to get in contact with the PO participant, but also seeks to possess or control it thereafter. The entity obtained can either be concrete (nach Öl bohren 'to drill for oil') or abstract (nach Lösungen suchen 'to look for solutions'). Since both cases have an 'intend to obtain'-interpretation, they are treated as variants of the same meaning rather than as separate constructions. Finally, instances of the PARTAKING type designate the subject referent's desire to partake in a particular state of affairs (sich nach Frieden sehnen 'to long for peace'). Schematically, our semantic classification can be diagrammed as follows:

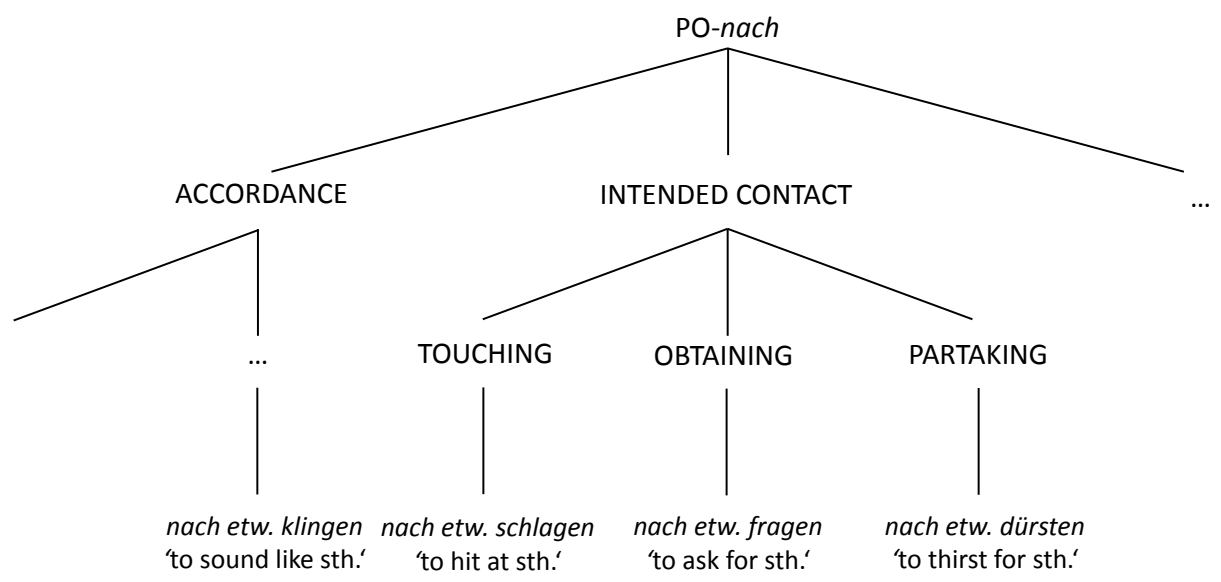

Figure 2: Partial semantic classification of nach-PO contructions 
Links to ambiguity overlap descriptions are provided for cases with interpretive overlap between different nach-constructions (cf. conative INTENDED CONTACT|TOUCHING vs. INTENDED CONTACT|OBTAINING). A synonymy overlap description is provided in connection with constructions with the preposition $\mathrm{um}$, which likewise has a family of INTENDED CONTACT uses (link not shown in figure 1). By contrast, no synonymy is posited between constructions with nach on the one hand and $\ddot{u} b e r$ and $z u$ on the other (however, such a link is posited between the TOPIC-meanings of über and $z u$ ).

Structurally, mappings from constructional argument roles to grammatical relations are standardly supplied for declarative active voice instances of the relevant construction (ich fragte ihn nach dem Weg 'I asked him for the way'), following established practice in German valency lexicography. Unless otherwise stated, it is assumed that constructions with accusative objects possess regular werden-passive voice allostructions (er wurde nach dem Weg gefragt 'He was asked for the way') that need not be stipulated on a construction-specific basis. Meaning differences between active and passive variants of a given argument structure construction are seen as independent of the specific argument structure construction in question and hence not covered in the resource. If a construction (or a specific group of predicates or individual predicate within this construction) does not possess a passive allostruction (cf. es verlangt ihn nach mehr 'he desires for more', literally 'it desires him for more' vs. ${ }^{*}$ er wird nach mehr verlangt 'he is desired for more'), this property is stipulated in the section on constructional form. Special mapping properties of instantiating predicates/groups of such predicates in the active voice (cf. ihn ${ }_{\mathrm{ACC}}$ dürstet/hungert) verlangt es nach etwas 'he thirsts/hungers/desires for something', literally: 'it thirsts/ hungers/desires him for something') are listed as allostructions of the declarative active "standard" realisation that are indexed for relevant verbs. Fully predictable, construction-independent deviations from the standard realisation (Frag nach dem Weg! 'Ask for the way!') are not covered by the constructional description at all. In view of the focus on verbal constructions, adjectivalised and nominalised argument structures are excluded, too.

By contrast, intransitive and transitive verbal expressions with the same semantic role of the PO (cf. nach etwas suchen 'to search for something' vs. etwas nach etwas durchsuchen 'to search something for something') are treated as structural variants of the same (semantically defined) PO-construction category. In such cases, the constructional description specifies the appropriate interpretation of the additional argument of the more complex variant and lists the predicates that permit (cf. (jemanden) nach etwas fragen 'to ask (someone) about something') or even require it (cf. jemanden nach etwas befragen 'to question someone about something'). Interactions with other argument structure constructions (jemanden/m nach etwas Löcher in den Bauch fragen 'to pester someone with questions about something', literally: 'to ask someone holes into the belly for something') are covered only impressionistically, since the analysis involves no systematic search for them. 


\section{Summary and conclusion}

In this paper, we have discussed potentials and problems of constructicography, the construction-based description of language in linguistic reference works. Using German prepositional object (PO) constructions (or, depending on the perspective, $\mathrm{PO}$ verbs and $\mathrm{PO}$ prepositions) as an example, we have first assessed their representation in different types of traditional linguistic reference works (dictionaries and grammars) and compared these treatments to a construction-based approach. We have argued that a construction-based treatment is superior, but faced with several challenges. Second, we have discussed what we believe to be the most fundamental of these problems, which we refer to as the grain size problem of constructional description. Finally, we have introduced the outline of a construction-based reference work of German PO constructions and illustrated how the problems discussed before are handled in this practical implementation.

Section 2 has argued that existing types of reference works are of limited use for a user interested in German PO constructions because they (i) fail to indicate that these constructions are systematically meaningful, (ii) cover specific PO meanings highly impressionistically at best, and (iii) are for the most part difficult to search for relevant information. To overcome these shortcomings, we have argued for a construction-based approach to the description of German prepositional objects that does not attribute their specific properties either to individual instantiating words (be it governing verbs or PO prepositions) or to general rules of grammar. Instead, we have suggested that German PO constructions are profitably described as a specific kind of verb argument structure construction in the construction grammar sense, each coming with its own meanings and usage preferences that deserve proper coverage in a suitable kind of linguistic reference work.

Having argued for the benefits of such a description, we have then turned to problems of implementing it in practice. Our discussion in section 3 has focused on the most pressing question raised by the switch to a construction-based perspective: which types of semantically and formally similar expressions should be included in a given description in the first place? Focusing on expressions with the preposition nach, grain size problems of constructional description were discussed with regard to meaning (3.1) and form (3.2). Semantically, we have pointed to problems incurred by both splitting (3.1.1) and lumping analyses (3.1.2) of constructional meaning, as well as to open questions for mixed approaches (like Boas 2010 and Herbst 2014) that seek to combine lexical (valency-based) and constructional (schema-based) approaches to argument structure. Regarding the form side of grammatical constructions, we have reviewed issues in connection with the identification of (obligatory) arguments of a construction, interactions between constructions of the same (PO-nach + resultative + possessive dative) and different grammatical types (PO-nach and werden-passive, PO-nach and adjectivalisation) as well as variation in the formal realisation of individual arguments, be it structural (cf. er ${ }_{\mathrm{NOM}} / \mathrm{ihn}_{\mathrm{ACC}} /$ 
ihm $_{\mathrm{DAT}}$ dürstet (es) nach etwas) or lexical in nature (cf. jemanden nach/zu/um/über etwas fragen).

Finally, section 4 has introduced a multi-layered approach to constructional description that synthesises lumping and splitting perspectives on the same data. Semantically, it was suggested that PO constructions can be described on three different levels: (i) top-level descriptions, which provide an account of the entire semantic space covered by all PO-constructions of a given PO-preposition (and their relations to specific adverbial source constructions), (ii) family-level decriptions, which provide an account of semantically coherent families of such constructions that can be differentiated from other families with the same PO-preposition, but different meanings, and (iii) construction-level descriptions, which provide an account of each member of these families, i.e. individual PO-constructions with their specific form, meaning and usage properties. We have sketched how such an approach can be implemented in a descriptive reference constructicon, indicating which kinds of information are provided where, and how a user can access different kinds of contents and browse between individual descriptions and associated quantitative analyses. To be sure, the way of presenting the data discussed in section 4 does not provide a theoretical solution to remaining open questions regarding lexical vs. constructional approaches to verb argument structure. Nevertheless, it shows that the problems raised in section 3 do not in principle preclude the formulation of a viable alternative to lexically based descriptions as found in e.g. traditional valency dictionaries. We therefore suggest that constructica provide an important addition to our descriptive repertoire that complements existing lexical resources from a pattern-based perspective in a way that will appeal to both professional (linguistic) and lay (e. g. learner) users of linguistic reference works alike.

Acknowledgement: We thank Dagobert Höllein, Ekaterina Laptieva and Edeltraud Winkler for comments and discussion and Sarina Streitel, Lena Rebhan and Anna Hackstein for their assistance in data coding and the preparation of the manuscript.

\section{Bibliography}

Boas, Hans C. (2003): A Constructional Approach to Resultatives. Stanford: Center for the Study of Language and Information. Amsterdam/Philadelphia: John Benjamins.

Boas, Hans C. (2010): The syntax-lexicon continuum in Construction Grammar. A case study of English communication verbs. In: Belgian Journal of Linguistics 24, 54-82.

Boas, Hans C. (2014): Zur Architektur einer konstruktionsbasierten Grammatik des Deutschen. In: Lasch, Alexander/Ziem, Alexander (eds.): Grammatik als Netzwerk von Konstruktionen. Sprachwissen im Fokus der Konstruktionsgrammatik. Berlin: de Gruyter, 37-63.

Cappelle, Bert (2006): Particle Placement and the case for "allostructions". In: Constructions Online SV1-7/2006, 1-28. [www.constructions-online.de, urn:nbn:de:0009-4-6839; ISSN 1860-2010; last access: July 10, 2019]. 
Collins Cobuild Grammar Patterns. [<http://arts-ccr-002.bham.ac.uk/ccr/patgram/>; last access: July 8, 2019].

DG = DUDEN - Die Grammatik. Eds. Eisenberg, Peter/Kunkel-Razum, Kathrin [Red.]. Mannheim/ Wien/Zürich: Dudenverlag, 8th edn. 2009 [1st edn. 1959].

DUW $=$ DUDEN - Deutsches Universalwörterbuch. Das umfassende Bedeutungswörterbuch der deutschen Gegenwartssprache. Rev. by Scholze-Stubenrecht, Werner. Berlin: Dudenredaktion, 8th edn. 2015 [1st edn. 1983].

Engelberg, Stefan (2019): Argumentstrukturmuster: Ein elektronisches Handbuch zu verbalen Argumentstrukturen im Deutschen. In: Czicza, Dániel/Dekalo, Volodymyr/Diewald, Gabriele (eds.): Konstruktionsgrammatik VI. Varianz in der konstruktionalen Schematizität. Tübingen: Stauffenburg, 13-38.

Engelen, Berhard (1975): Untersuchungen zu Satzbauplan und Wortfeld in der geschriebenen Sprache der Gegenwart. Vol. 1. München: Hueber.

Erlangen Valency Patternbank. [<http://www.patternbank.uni-erlangen.de/cgi-bin/patternbank. cgi>; last access: July 8, 2019].

$\mathrm{E}-\mathrm{VALBU}=$ Elektronisches Valenzwörterbuch deutscher Verben. [Institut für Deutsche Sprache: "Wörterbuch zur Verbvalenz". Grammatisches Informationssystem grammis. DOI: 10.14618/ evalbu. [<Permalink: https://grammis.ids-mannheim.de/verbvalenz〉; last access: May 19, 2019].

Fillmore, Charles J./Lee-Goldman, Russell R./Rhomieux, Russell (2012): The FrameNet Constructicon. In: Boas, Hans C./Sag, Ivan A. (eds.): Sign-Based Construction Grammar. CSLI Publications, 309-372.

Goldberg, Adele E. (1995): Constructions. A Construction Grammar Approach to Argument Structure. Chicago/London: The University of Chicago Press.

Goldberg, Adele E. (2006): Constructions at Work. The Nature of Generalization in Language. Oxford: Oxford University Press.

Goldberg, Adele E. (2016): Partial productivity of linguistic constructions: Dynamic categorization and statistical pre-emption. In: Language and Cognition 8 (2016), 369- 390.

Goldberg, Adele E. (2019): Explain Me This. Creativity, Competition, and the partial Productivity of Constructions. Princeton University Press.

Goldberg, Adele E./Jackendoff, Ray (2004). The English resultative as a family of constructions. In: Language 80(3), 532-568.

Helbig, Gerhard/Buscha, Joachim (2017): Deutsche Grammatik. Ein Handbuch für den Ausländerunterricht. Stuttgart: Ernst Klett Sprachen [1st edn. 2001].

Herbst, Thomas (2014): The valency approach to argument structure constructions. In: Herbst, Thomas/Schmid, Hans-Jörg/Faulhaber, Susen (eds.): Constructions - Collocations - Patterns. Berlin/Boston: de Gruyter, 159-208.

Herbst, Thomas (2017): Wörterbuch war gestern. Programm für ein unifiziertes Konstruktikon! In: Schierholz, Stefan J. et al. (eds.): Wörterbuchforschung und Lexikografie. Berlin/Boston: de Gruyter, 169-206.

Hilpert, Martin (2009): The German mit-predicative construction. In: Constructions and Frames 1(1), 29-55.

Höllein, Dagobert (2019): Präpositionalobjekt vs. Adverbial. Die semantischen Rollen der Präpositionalobjekte. Berlin/Boston: Walter de Gruyter.

Kiss, Tibor et al. (2016): Ein Handbuch für die Bestimmung und Annotation von Präpositionsbedeutungen im Deutschen. [2nd. edn., 1st edn. 2014]. Bochum: Sprachwissenschaftliches Institut, Ruhr-Universität Bochum.

Langacker, Ronald W. (1987): Foundations of Cognitive Grammar. Vol. 1. Stanford: Stanford University Press. 
Langacker, Ronald W. (2000). A dynamic usage-based model. In: Barlow, Michael/Kemmer, Suzanne (eds.), Usage-based models of language. Stanford: Stanford University Press, 1-63.

Langacker, Ronald W. (2009): Investigations in Cognitive Grammar. Berlin/New York: Mouton de Gruyter.

Levin, Beth (1993): English verb classes and alternations. A preliminary Investigation. Chicago/ London: The University of Chicago Press.

Müller, Stefan (2002): Complex Predicates. Verbal Complexes, Resultative Constructions, and Particle Verbs in German. Stanford: CSLI Publications.

Müller, Stefan/Wechsler, Stephen (2014): Lexical Approaches to Argument Structure. In: Theoretical Linguistics 40 (1-2), 1-76.

The Oxford English Dictionary. Being a corrected re-issue with an introduction, supplement, and bibliography of A New English Dictionary on Historical Principles founded mainly on the materials collected by The Philological Society. Vol. II C. Oxford: Clarendon Press. [Rpt. 1963, 1st publ. 1961].

Pattern Dictionary of English Prepositions. [<https://www.clres.com/pdep.html〉; last access: July 8, 2019].

Perek, Florent (2014): Rethinking constructional polysemy: The case of the English conative construction. In Glynn, Dylan/Robinson, Justyna A. (eds.): Corpus Methods for Semantics. Quantitative studies in polysemy and synonymy. Amsterdam: John Benjamins, 61-85.

Perek, Florent (2015): Argument Structure in Usage-Based Construction Grammar. Experimental and Corpus-based Perspectives. Amsterdam: John Benjamins.

Pittner, Karin (1996): Adverbiale im Deutschen. Untersuchungen zu ihrer Stellung und Interpretation. Habilitationsschrift, Universität Stuttgart.

Proost, Kristel (2015): Die sucH-Konstruktion als eine Familie von Argumentstrukturmustern. In: Proost, Kristel/Winkler, Edeltraud: Familienähnlichkeiten deutscher Argumentstrukturmuster. Mannheim: Institut für Deutsche Sprache, 10-41. [<https://pub.ids-mannheim.de/laufend/ opal/pdf/opal2015-1.pdf>; doi: 10.14618/opal_01-2015. last access: July 8, 2019].

Proost, Kristel (2017): The role of verbs and verb classes in identifying German search-constructions. In: Ruiz de Mendoza lbáñez, Francisco José/Luzondo Oyón, Alba/Pérez Sobrino, Paula (eds.): Constructing Families of Constructions. Analytical Perspectives and Theoretical Challenges. Amsterdam/Philadelphia: John Benjamins, 17-51.

Reddy, Michael (1993). The conduit metaphor: A case of frame conflict in our language about language. In: Ortony, Andrew (ed.): Metaphor and Thought. Cambridge: Cambridge University Press [2nd edn., 1st edn. 1979], 284-324.

Rostila, Jouni (2005): Zur Grammatikalisierung bei Präpositionalobjekten. In: Leuschner, Torsten/ Mortelmans, Tanja/De Groodt, Sarah (eds.): Grammatikalisierung im Deutschen. Berlin/New York: de Gruyter, 135-166.

Rostila, Jouni (2007): Konstruktionsansätze zur Argumentmarkierung im Deutschen. Tampere: University of Tampere Press.

Rostila, Jouni (2014): Inventarisierung als Grammatikalisierung: Produktive Präpositionalobjekte und andere grammatikalisierte Linking-Muster. In: Lasch, Alexander/Ziem, Alexander (eds.): Grammatik als Netzwerk von Konstruktionen. Sprachwissen im Fokus der Konstruktionsgrammatik. Berlin: de Gruyter, 97-116.

Rostila, Jouni (2015): Inside Out: Productive German Prepositional Objects as an Example of Complements Selecting Heads. In: Höglund, Mikko/Rickman, Paul/Rudanko, Juhani/Havu, Jukka (eds.): Perspectives on Complementation. Structure, Variation and Boudaries. E-Book. Palgrave Macmillan, 34-51.

Rostila, Jouni (2018): Argument strucrure constructions among German prepositional objects. In: Boas, Hans C./Ziem, Alexander (eds.): Constructional Approaches to Syntactic Structures in German. Berlin: De Gruyter Mouton, 406-446. 
Schmitz, Werner (1964): Der Gebrauch der deutschen Präpositionen. München: Hueber.

Schröder, Jochen (1986): Lexikon deutscher Präpositionen. Leipzig: VEB Verlag Enzyklopädie.

Schulz, Dora/Griesbach, Heinz (1982). Grammatik der deutschen Sprache. Neubarbeitung von Heinz Griesbach [11th edn., 1st edn. 1960]. München: Max Hueber Verlag.

Stefanowitsch, Anatol/Gries, Stefan Th. (2003): Collostructions. Investigating the interaction of words and constructions. In: International Journal of Corpus Linguistics 8:2, 209-243.

Tuggy, David (1993). Ambiguity, polysemy, and vagueness. In: Cognitive Linguistics 4-3, 273-290.

Uhrig, Peter (2015). "Why the Principle of No Synonymy is overrated.” In: Thomas Herbst and Susen Faulhaber (eds.): Constructions - Aspects of Construction Grammar. ZAA Themenheft 2015/3.

VALBU = Valenzwörterbuch deutscher Verben. Schumacher, Helmut/Kubczak, Jacqueline/Schmidt, Renate/de Ruiter, Vera. Tübingen: Narr, 2004.

Von Polenz, Peter (1969): Der Pertinenzdativ und seine Satzbaupläne. In: Engel, Ulrich/Grebe, Paul/Rupp, Heinz (eds.): Festschrift für Hugo Moser zum 60. Geburtstag am 19. Juni 1969. Düsseldorf: Schwann, 146-171.

Wegener, Heide (1985). Der Dativ im heutigen Deutsch. Tübingen: Narr.

Weinrich, Harald (1993). Textgrammatik der deutschen Sprache. Unter Mitarbeit von Maria Thurmair, Eva Breindl und Eva-Maria Willkop. Mannheim/Leipzig/Wien/Zürich: Dudenverlag.

Welke, Klaus (2015): Passivanalyse in der Konstruktionsgrammatik. Eine Erwiderung auf Werner Abraham. In: Deutsche Sprache 4/2, 97-117.

Wonnacott, Elizabeth/Newport, Elissa L./Tanenhaus, Michael K. (2007): Acquiring and processing verb argument structure. Distributional learning in a miniature language. In: Cognitive Psychology 56, 165-209.

Zeschel, Arne (2018): Musterbasierte Lexikografie und das Konstruktikon. Probleme und Perspektiven am Beispiel des deutschen in-Prädikativs. In: Steyer, Kathrin (ed.): Sprachliche Verfestigung. Wortverbindungen, Muster, Phrasem-Konstruktionen. Tübingen: Narr, 49-72.

Zeschel, Arne (2019): Zum Bedeutungsgehalt von Präpositionalobjekten: Eine musterbasierte Analyse verbaler Argumentstrukturen mit der Präposition vor. In: Czicza, Dániel/Dekalo, Volodymyr/Diewald, Gabriele (eds.): Konstruktionsgrammatik VI. Varianz in der konstruktionalen Schematizität. Tübingen: Stauffenburg, 39-77.

Ziem, Alexander (2014): Konstruktionsgrammatische Konzepte eines Konstruktikons. In: Lasch, Alexander/Ziem, Alexander (eds.): Grammatik als Netzwerk von Konstruktionen. Sprachwissen im Fokus der Konstruktionsgrammatik. Berlin: Walter de Gruyter, 15-34.

Zifonun, Gisela/Hoffmann, Ludger/Strecker, Bruno (1997). Grammatik der deutschen Sprache. Vol. 3. Berlin/New York: De Gruyter. 